\title{
Climatic Change
}

\section{Greater probability of extreme precipitation under $1.5^{\circ} \mathrm{C}$ and $2^{\circ} \mathrm{C}$ warming limits over East-Central Asia \\ --Manuscript Draft--}

\begin{tabular}{|c|c|c|}
\hline Manuscript Number: & \multicolumn{2}{|l|}{ CLIM-D-19-00396R2 } \\
\hline Full Title: & \multicolumn{2}{|c|}{$\begin{array}{l}\text { Greater probability of extreme precipitation under } 1.5^{\circ} \mathrm{C} \text { and } 2^{\circ} \mathrm{C} \text { warming limits over } \\
\text { East-Central Asia }\end{array}$} \\
\hline Article Type: & \multicolumn{2}{|l|}{ Research Article } \\
\hline Corresponding Author: & \multicolumn{2}{|c|}{$\begin{array}{l}\text { Haipeng Yu } \\
\text { Northwest Institute of Eco-Environment and Resources, Chinese Academy of Sciences } \\
\text { CHINA }\end{array}$} \\
\hline \multicolumn{3}{|l|}{$\begin{array}{l}\text { Corresponding Author Secondary } \\
\text { Information: }\end{array}$} \\
\hline Corresponding Author's Institution: & \multicolumn{2}{|c|}{ Northwest Institute of Eco-Environment and Resources, Chinese Academy of Sciences } \\
\hline \multicolumn{3}{|l|}{$\begin{array}{l}\text { Corresponding Author's Secondary } \\
\text { Institution: }\end{array}$} \\
\hline First Author: & \multicolumn{2}{|l|}{ Meng Zhang } \\
\hline \multicolumn{3}{|l|}{ First Author Secondary Information: } \\
\hline \multirow[t]{6}{*}{ Order of Authors: } & \multicolumn{2}{|l|}{ Meng Zhang } \\
\hline & \multicolumn{2}{|l|}{ Haipeng Yu } \\
\hline & \multicolumn{2}{|l|}{ Andrew D. King } \\
\hline & \multicolumn{2}{|l|}{ Yun Wei } \\
\hline & \multicolumn{2}{|l|}{ Jianping Huang } \\
\hline & \multicolumn{2}{|l|}{ Yu Ren } \\
\hline \multicolumn{3}{|c|}{ Order of Authors Secondary Information: } \\
\hline \multirow[t]{4}{*}{ Funding Information: } & $\begin{array}{l}\text { National Natural Science Foundation of } \\
\text { China } \\
(41705077)\end{array}$ & Not applicable \\
\hline & $\begin{array}{l}\text { National Natural Science Foundation of } \\
\text { China } \\
(41630426)\end{array}$ & Not applicable \\
\hline & $\begin{array}{l}\text { National Key Research and Development } \\
\text { Program of China } \\
\text { (2017YFC1502305) }\end{array}$ & Not applicable \\
\hline & $\begin{array}{l}\text { Australian Research Council } \\
\text { (DE180100638) }\end{array}$ & Dr. Andrew D. King \\
\hline Abstract: & \multicolumn{2}{|c|}{$\begin{array}{l}\text { East-Central Asia is one of the most vulnerable and sensitive regions to climate } \\
\text { change, and the variability of extreme precipitation attracts great attention due to the } \\
\text { large population and the importance of its economy. Here, three special runs with the } \\
\text { Community Earth System Model (CESM) are used to project the changes in } \\
\text { representative extreme precipitation indices (Rx1day, Rx5day, R95p, SDII) over East- } \\
\text { Central Asia under the } 1.5^{\circ} \mathrm{C} \text { and } 2^{\circ} \mathrm{C} \text { Paris Agreement limits. The results indicate that } \\
\text { Rx1day and Rx } 5 \text { day will increase by } 28 \% \text { and } 15 \% \text {, respectively, under the } 1.5^{\circ} \mathrm{C} \\
\text { warming level relative to the historical period }(1971-2000) \text {. Most areas over East- } \\
\text { Central Asia are projected to experience an accelerated increase in response to a } \\
\text { further } 0.5^{\circ} \mathrm{C} \text { warming. Specifically, humid areas (HAs) are projected to experience a } \\
\text { greater increase in R95p annual days and area fraction, whereas arid and semiarid } \\
\text { areas (ASAs) may have three times higher risks. The proportion of extreme } \\
\text { precipitation in total will increase } ~ \\
\text { warming. Holding global warming at } 1.5^{\circ} \mathrm{C} \text { instead of } 2^{\circ} \mathrm{C} \text { reduces the occurrence of } \\
\text { R95p annual days by } \sim \text { three days/year in humid areas and } \sim \text { one day/year in ASAs. For }\end{array}$} \\
\hline
\end{tabular}


SDII, most HAs will experience $0.2-0.6 \mathrm{~mm} /$ day and $0.2-0.4 \mathrm{~mm} /$ day increases in $1.5^{\circ} \mathrm{C}$ or $2^{\circ} \mathrm{C}$ warming limits, especially in Southeast China and the Himalayas. Therefore, limiting global warming to under $1.5^{\circ} \mathrm{C}$ is beneficial to reducing the occurrence and associated impact of precipitation extremes in East-Central Asia.

\section{Response to Reviewers:}

We are very grateful for the positive reviews of the manuscript and the detailed advice with constructive comments, which helped us to improve the article significantly. We accept all the proposed suggestions. Following these suggestions, we have revised the manuscript extensively, all the issues have been addressed. The description of $1.5^{\circ} \mathrm{C}$ and $2^{\circ} \mathrm{C}$ warming limits in Section 2.1 has been modified. All the writing mistakes raised by Reviewer \#2 has been revised one-by-one. Besides, the English of whole manuscript has been edited by Springer Nature English Language Editting (Order ID KXBTQZK5). Please find all the corrections in the revised manuscript with tracked changes. 
Greater probability of extreme precipitation under $1.5^{\circ} \mathrm{C}$ and $2^{\circ} \mathrm{C}$ warming limits over East-Central Asia

Meng Zhang ${ }^{1,2}$, Haipeng Yu ${ }^{1,3}$, Andrew D. King ${ }^{4}$, Yun Wei², Jianping Huang ${ }^{5}$, Yu Ren ${ }^{2}$

${ }^{1}$ Key Laboratory of Land Surface Process and Climate Change in Cold and Arid Regions, Northwest Institute of Eco-Environment and Resources, Chinese Academy of Sciences, Lanzhou, China

${ }^{2}$ Key Laboratory for Semi-Arid Climate Change of the Ministry of Education, College of Atmospheric Sciences, Lanzhou University, Lanzhou, China

${ }^{3}$ Key Laboratory of Arid Climatic Change and Disaster Reduction in Gansu Province, Key Open Laboratory of Arid Climatic Change and Disaster Reduction in CMA, Institute of Arid Meteorology, CMA, Lanzhou, China ${ }^{4}$ ARC Centre of Excellence for Climate Extremes, School of Earth Sciences, University of Melbourne, Melbourne 3010, Australia

${ }^{5}$ Collaborative Innovation Center for Western Ecological Safety, Lanzhou University, Lanzhou, China

Corresponding author: Haipeng Yu (hpyu09@1zu.edu.cn)

Additional author: Meng Zhang (zhangm2012@lzu.edu.cn)

Andrew D. King (andrew.king@ unimelb.edu.au)

Yun Wei (weiy16@lzu.edu.cn)

Jianping Huang (hjp@lzu.edu.cn)

Yu Ren (yren15@1zu.edu.cn) 


\section{Abstract}

East-Central Asia is one of the most vulnerable and sensitive regions to climate change, and the variability of extreme precipitation attracts great attention due to the large population and the importance of its economy. Here, three special runs with the Community Earth System Model (CESM) are used to project the changes in representative extreme precipitation indices (Rx1day, Rx5day, R95p, SDII) over East-Central Asia under the $1.5^{\circ} \mathrm{C}$ and $2{ }^{\circ} \mathrm{C}$ Paris Agreement limits. The results indicate that Rx1day and Rx5day will increase by $28 \%$ and $15 \%$, respectively, under the $1.5^{\circ} \mathrm{C}$ warming level relative to the historical period (1971-2000). Most areas over East-Central Asia are projected to experience an accelerated increase in response to a further $0.5^{\circ} \mathrm{C}$ warming. Specifically, humid areas (HAs) are projected to experience a greater increase in R95p annual days and area fraction, whereas arid and semiarid areas (ASAs) may have three times higher risks. The proportion of extreme precipitation in total will increase $\sim 10 \%$ in most HAs in response to the $0.5^{\circ} \mathrm{C}$ additional warming. Holding global warming at $1.5^{\circ} \mathrm{C}$ instead of $2^{\circ} \mathrm{C}$ reduces the occurrence of R95p annual days by three days/year in humid areas and one day/year in ASAs. For SDII, most HAs will experience 0.2-0.6 mm/day and 0.2-0.4 $\mathrm{mm} /$ day increases in $1.5^{\circ} \mathrm{C}$ or $2^{\circ} \mathrm{C}$ warming limits, especially in Southeast China and the Himalayas. Therefore, limiting global warming to under $1.5^{\circ} \mathrm{C}$ is beneficial to reducing the occurrence and associated impact of precipitation extremes in East-Central Asia.

Keywords: extreme precipitation, $1.5^{\circ} \mathrm{C}$ and $2^{\circ} \mathrm{C}$ warming limits, East-Central Asia, arid and semiarid areas, humid areas 


\section{Introduction}

As a meteorological phenomenon, extreme precipitation is responsible for many catastrophes and often causes disasters such as floods, which have great impacts on economic development, social stability and people's livelihoods (Orlowsky and Seneviratne, 2012; Yang et al., 2013; Scherrer et al., 2016). For instance, prolonged heavy precipitation led to the worst flooding in Pakistan's history in 2010, resulting in nearly 3,000 deaths and affecting 20 million people. In Nara Prefecture of Japan, the 72-hour rainfall record was broken in 2011, and that event resulted in 73 deaths and 20 missing (Coumou and Rahmstorf, 2012). It is crucial that the understanding of extreme precipitation changes be improved to better prepare, adapt and mitigate the impacts of future events as the climate changes.

Due to the effect of land-sea thermal differences and human activities, East-Central Asia $\left(10^{\circ}-55^{\circ} \mathrm{N}, 60^{\circ}-150^{\circ} \mathrm{E}\right)$ is one of the world's most vulnerable regions to extreme precipitation and its consequences (Zhai et al., 2005; Ren and Zhou, 2014; Zhao et al., 2015; Lin et al., 2016; Guan et al., 2017; Zhou et al., 2018). Given the impacts of precipitation extremes, such extremes have become a topic of interest in recent years, with efforts to improve the understanding of historic changes and future projections especially prominent (Alexander et al., 2006; Kharin et al., 2013; Sillmann et al., 2013a; Sillmann et al., 2013b). Since the Paris Agreement set a goal for limiting global warming below $2^{\circ} \mathrm{C}$ and preferentially to $1.5^{\circ} \mathrm{C}$ relative to pre-industrial levels, the variation in extreme climate conditions under future warming scenarios has also become an area of active research (Zhou and Chen, 2015; Chen and Sun, 2018; Dosio and Fischer, 2018; Li et al., 2018; Wei et al., 2019). Lin et al. (2018) indicated that the average precipitation in China will increase by $11.6 \%\left(1.5^{\circ} \mathrm{C}\right)$ and $13.3 \%\left(2^{\circ} \mathrm{C}\right)$ based on 1976-2005. Chen and Sun (2017) pointed out that human influence will cause half of the occurrence probability increase of severe extremes in China. Zhang et al. (2018) indicated that $0.5^{\circ} \mathrm{C}$ further warming would aggravate areal and population exposures to once-in-20-year extreme precipitation events by $25 \%$ in East Asia. Kusunoki pointed out that almost all eastern China areas are projected to 
experience more precipitation during 2079 to 2099. Other studies have also pointed out that continued global temperature increases are projected to induce more extreme precipitation events in the future (Endo et al., 2017; Wang et al., 2017). There are several methods that can be used to form projections for climate extremes in different warmer worlds (e.g., the Coupled Model Intercomparison Project phase 5 (CMIP5) time-sampling and prescribed sea surface temperature (SST) simulations) (Mitchell et al., 2016; Schleussner et al., 2016; King et al., 2017). CMIP5 time sampling may utilize all four representative concentration pathways (RCPs) to generate a large sample of model years, but these are based on transient climates for low-end global warming limits, such as $1.5^{\circ} \mathrm{C}$ and $2^{\circ} \mathrm{C}$. Atmosphere-only model simulations use prescribed SSTs, representing the recent period but with additional warming, to project future climates. However, there is an assumption that the recent period is representative of current climate variability and that coupled processes are not important to the extreme being investigated (Fischer et al., 2018). Here, we utilized three Community Earth System Model (CESM) experiments to analyze the spatiotemporal difference between the $1.5^{\circ} \mathrm{C}$ and $2{ }^{\circ} \mathrm{C}$ warming limits and the recent historical period (Sanderson et al., 2017; Zhang et al., 2019). To our knowledge, research on East-Central Asia extreme precipitation predictions using CESM $1.5^{\circ} \mathrm{C}$ and $2^{\circ} \mathrm{C}$ low warming runs (LWR) is scarce.

Precipitation in East-Central Asia is distributed unevenly owing to the influence of the monsoon and warm moist air from the ocean (Li et al., 2016; Xing et al., 2016). Monsoon areas have abundant precipitation, while inland areas, where there is a relative lack of water vapor source, have little precipitation but high potential evapotranspiration. This difference in the mean climate state and interannual variability in the monsoon poses a challenge to water supply management (Huang et al., 2016a; Huang et al., 2017). The difference in background climate state and in precipitation extremes between these regions makes it necessary to analyze them separately. Thus, to be more precise and objective, we divide East-Central Asia into two subparts based on the aridity index (AI): humid areas (HAs) and arid and semiarid areas (ASAs). ASAs are defined as regions with an AI less than 0.65 
108 (Middleton and Thomas, 1997). We utilized the AI provided by Feng and Fu (2013)

109 and calculated for the historical period as a basis for the dry-wet division. For more

110 details about the AI, please refer to (Scheff and Frierson, 2014; Huang et al., 2016b).

111 In this paper, we compare and analyze four relevant and widely used extreme

112 precipitation indices (Rx1day, Rx5day, R95p and SDII) (Karl et al., 1999; Peterson et

113 al., 2001) and try to answer the following three questions: (1) Will a remarkable

114 difference appear in East-Central Asia under a $1.5^{\circ} \mathrm{C}$ or $2^{\circ} \mathrm{C}$ global warming future?

115 (2) What is the difference due to a further $0.5^{\circ} \mathrm{C}$ warming? (3) Are there differences in 116 projections for ASAs and HAs? 


\section{Data and Methods}

\subsection{Model data}

We used the fully coupled climate model CESM released by the National Center for Atmospheric Research (NCAR) for our analysis of extreme precipitation projections under $1.5^{\circ} \mathrm{C}$ and $2^{\circ} \mathrm{C}$ global warming limits (Hurrell et al., 2013). The CESM LWR comprises a 10 -member ensemble for $1.5^{\circ} \mathrm{C}$ and $2^{\circ} \mathrm{C}$ scenarios called 1 pt5 and 2pt, respectively (Kay et al., 2015; Sanderson et al., 2016). By setting the radiative forcing of greenhouse gases, the global mean temperature relative to pre-industrial levels would rise monotonically to $1.5^{\circ} \mathrm{C}\left(2^{\circ} \mathrm{C}\right)$ by $2090-2100$ under LWR 1pt5 (2pt) scenarios. We also used RCP4.5 and RCP8.5 to provide further comparisons. The number of runs in the CESM models under the RCP4.5 scenarios is 15 , and under the RCP8.5 scenarios, it is 30 . Under RCPs, we define the $1.5^{\circ} \mathrm{C}\left(2^{\circ} \mathrm{C}\right)$ global warming level as the 11-year window based on the centers of chosen years (RCP4.5 and RCP8.5) when the 11-year mean temperature rise to $1.5^{\circ} \mathrm{C}\left(2^{\circ} \mathrm{C}\right)$ relative to pre-industrial levels. Therefore, the CESM LWR scenario represents the equilibrium climate response while the RCPs represent transient climate response scenarios. The equilibrium climate response scenario means that the average global warming will stabilize at $1.5^{\circ} \mathrm{C}$ or $2^{\circ} \mathrm{C}$ by the end of the 21 st century. Moreover, the carbon dioxide equivalence emission is matched with global temperature rises. For transient climate responses, such as RCP4.5 and RCP8.5, the global mean temperature would pass through $1.5^{\circ} \mathrm{C}$ or $2^{\circ} \mathrm{C}$, and the final increase exceeds these two warming limits. This response might overestimate the temperature increase and cause some related influence. The dynamic and thermodynamic systems of climate model simulation are not in equilibrium. Based on the climate model work principle, the equilibrium response scenario is considered more acceptable than the transient one. More details about CESM experiments can be found in Sanderson et al. (2017).

\subsection{Extreme precipitation indices}

Four extreme precipitation indices defined by the Expert Team for Climate 
Change Detection Monitoring and Indices (ETCCDI) were selected for analysis of the changes in extreme precipitation events in warmer futures (Perkins et al., 2012; Donat et al., 2013; Perkins and Alexander, 2013). Further details of the four selected extreme precipitation indices are provided in Table 1.

Table 1: Core set of four selected extreme indices recommended by the ETCCDI.

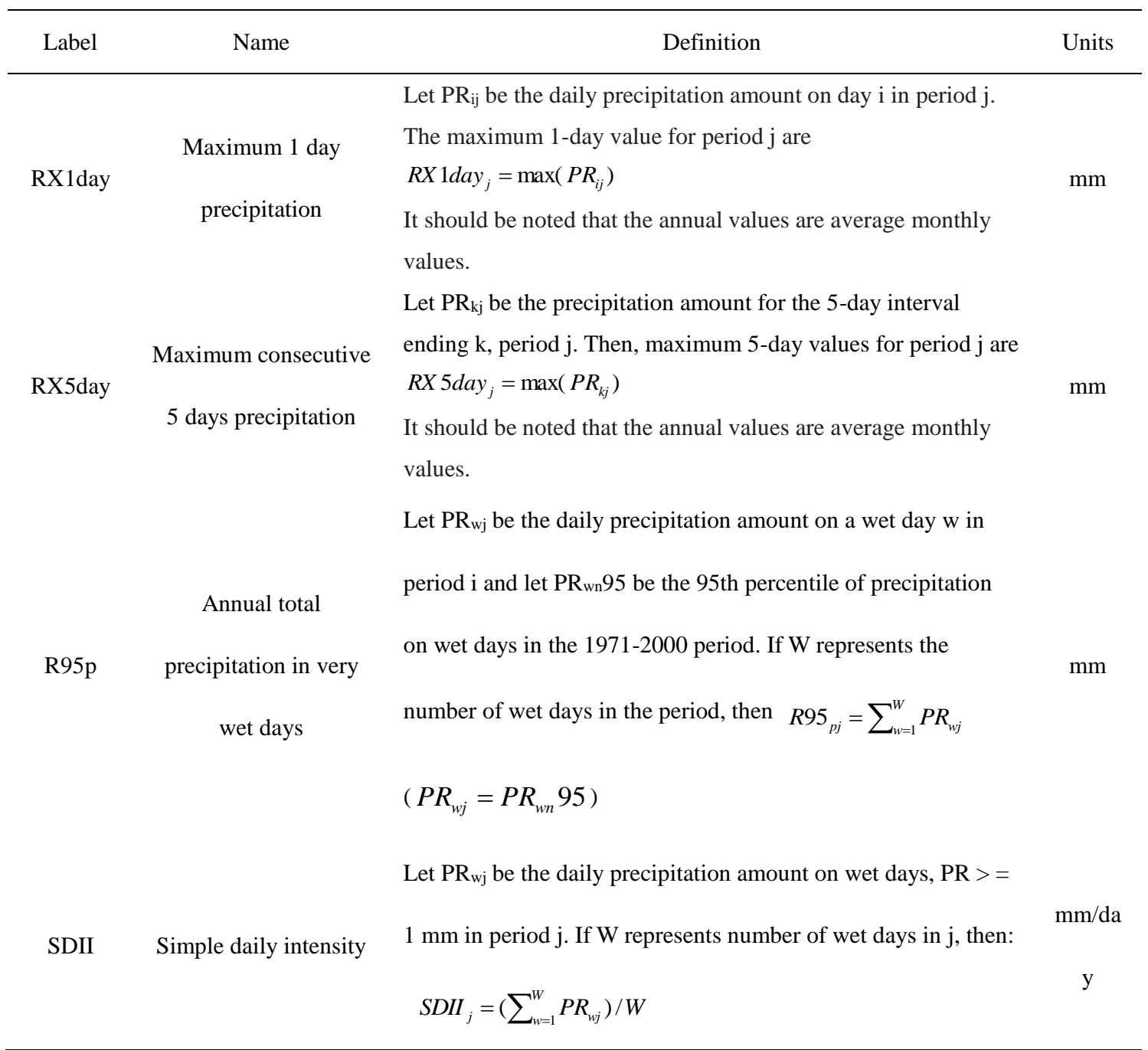

Rx1day and Rx5day are probably related to specific and possibly meteorologically distinct extreme precipitation events. R95p is useful in reflecting the absolute value change in total annual extreme precipitation. SDII is used to measure the intensity of precipitation on wet days. Together, these indices are useful in extending our understanding of the changing likelihood of extreme precipitation under $1.5^{\circ} \mathrm{C}$ and $2^{\circ} \mathrm{C}$ warming limits. 


\subsection{Probability ratio}

The probability ratio (PR) is a metric to measure the probability of a specific

162

163

164

165

166

167

168

169

170

171

172

173

174

175

176

event having changed. The formula and method come from the epidemiological field. Since being introduced to the climate change study area, PR has been used to detect the risk of the events occurring. The PR as a detection and attribution method represents the extent to which external forcing, such as global warming and the overall anthropogenic influence on the climate, affect extreme precipitation events (Fischer and Knutti, 2015). The formula used is as shown in (1).

$$
\mathrm{PR}=\mathrm{P}_{1} / \mathrm{P}_{0}
$$

Here, $\mathrm{P}_{0}$ refers to the extreme precipitation indices in a historical period (note that this is different from many event attribution studies, where an approximation for a pre-industrial climate is represented by $\mathrm{P}_{0}$ ) and $\mathrm{P}_{1}$ represents the probability of the event under a $1.5^{\circ} \mathrm{C}$ or $2^{\circ} \mathrm{C}$ warming future. The PR statistic can be considered an indicator for the change in the probability of the extreme precipitation indices: the reference value is 1.0 , which would mean future likelihoods are the same as now. If PR>1.0, the occurrence (for Rx1day and Rx5day) or intensity (for R95p and SDII) of precipitation extremes will increase, and vice versa (Stone and Allen, 2005). 


\section{Results}

\subsection{Spatiotemporal change in the four indices}

For Rx1day under $1.5^{\circ} \mathrm{C}$ global warming, an obvious dividing line could be found in all four experiments (Figure 1-4). It is worth mentioning that this boundary also separates ASAs from HAs. Southeast China and the Himalayas witness a rise of over $2 \mathrm{~mm}$, based on the CESM LWR simulations, while the rest of the HAs experience a projected increase of $1-2 \mathrm{~mm}$ in a $1.5^{\circ} \mathrm{C}$ world (Figure 1(a)). The spatial patterns of RCP4.5 and RCP8.5 are similar to that in LWR. Nevertheless, the absolute increase in Southeast China is lower in the RCPs than in the LWR simulations (Figure 1(c)(e)). There is consistency between Rx1day and Rx5day projections in their spatial pattern. There is a projected increase in Rx5day of over $6 \mathrm{~mm}$ in Southeast China and the Himalayas according to LWR, three times as much as for Rx1day (Figure 2(a)). The R95p index is projected to increase by over $200 \mathrm{~mm}$ under $1.5^{\circ} \mathrm{C}$ global warming, such that a larger portion of the total annual precipitation in HAs, such as Southeast China and the Himalayas, is due to extreme rainfall (Figure 3(a)). Likewise, RCP4.5 and RCP8.5 in Rx5day and R95p increase less compared with the LWR simulations (Figure 2(c)(e) and Figure 3(c)(e)). SDII represents the simple daily intensity of precipitation on wet days. If SDII increases in the future, the risk for extreme precipitation will be higher. From Figure 4, we can see that most HAs are projected to experience a $0.5 \mathrm{~mm} /$ day increase under $1.5^{\circ} \mathrm{C}$ relative to the historical period, whereas SDII in North India will decrease by approximately $0.5 \mathrm{~mm} /$ day (Figure 4(a)(c)(e)).

For a further $0.5^{\circ} \mathrm{C}$ warming in Rx1day, some regions (Southeast China and the Himalayas) still experience a modest increase of approximately $0.5-1 \mathrm{~mm}$ (Figure 1(b)). Additionally, the difference in spatial pattern between the LWR and the other two experiments narrows (Figure 1(d)(f)). Some regions, such as North China, North India and Pakistan, near the dry-wet transition zone, are simulated to experience a projected minor decrease in Rx1day. In these regions, increases in temperature and extreme precipitation are not positively related. This phenomenon might be induced 
by hydrologic cycle issues in the CESM. North India and Pakistan are located in the subtropical ASAs, which belongs to the sink branch of the Hadley circulation. An additional $0.5^{\circ} \mathrm{C}$ warming from $1.5^{\circ} \mathrm{C}$ to $2^{\circ} \mathrm{C}$ is likely to cause more moisture divergence and then moisture content reduction (Zhang et al., 2019). Thus, North India and Pakistan are projected to see decreasing trends in some extreme precipitation indices. The same phenomenon also occurs in Rx5day, but the amplitude is twice as high as that for Rx1day (Figure 2(b)(d)(f)). Figure 3(b)(d)(f) illustrates that a further $0.5^{\circ} \mathrm{C}$ warming is associated with an almost $100 \mathrm{~mm}$ increase in $\mathrm{R} 95 \mathrm{p}$ in most HAs, illustrating a substantial benefit of keeping global warming to the more ambitious $1.5^{\circ} \mathrm{C}$ Paris limit. Compared with the $200 \mathrm{~mm}$ rise under the $1.5^{\circ} \mathrm{C}$ scenario relative to the historical period, a sharp acceleration appears in the $2^{\circ} \mathrm{C}$ target relative to the $1.5^{\circ} \mathrm{C}$ target. The increasing or decreasing tendency of SDII is still maintained in the mentioned areas (Figure 4(b)(d)(f)).

The spatiotemporal change in percentage is different from that in absolute value mentioned before (Figures S1-S4). The change in the absolute value of extreme precipitation in ASAs is relatively small compared with that in HAs. However, under the $1.5^{\circ} \mathrm{C}$ and $2^{\circ} \mathrm{C}$ warming futures, there will be a sharp increase in the extreme precipitation percentage in most ASAs. The specific increases in ASAs in Rx1day, Rx5day, R95p and SDII under $1.5^{\circ} \mathrm{C}$ relative to the historical period are $20-40 \%$, $10-30 \%, 100-200 \%$ and $5-15 \%$, respectively. The additional $0.5^{\circ} \mathrm{C}$ warming provides a further 5-10\% increase in both Rx1day and Rx5day. For R95p, the average increase is $30-50 \%$. SDII in most ASAs is projected to experience a 2-4\% increase, although North India and Pakistan will witness a slight decrease. In summary, most ASAs may experience more extreme precipitation events in the warming future.

\subsection{Probability ratio change in Rx1day and Rx5day}

The absolute value changes in extreme precipitation under the $1.5^{\circ} \mathrm{C}$ and $2{ }^{\circ} \mathrm{C}$ warming limits show how rainfall extremes are projected to alter in the future, but PR values provide likelihood changes in extremes that help inform decision-making. Figure 5 shows the statistical distribution of PR values by gridbox in Rx1day and 
Rx5day under the $1.5^{\circ} \mathrm{C}$ and $2^{\circ} \mathrm{C}$ global warming limits relative to the historical period. According to Figure 5(a)-(b), only 5\% of all grid points see a decrease in Rx1day, and the rest of the area is projected to experience increases in this index, especially for the changes higher than the 90th percentile, which rise at a higher rate. For Rx5day, the proportion of all grid points that experience a PR below one increases from $5 \%$ to $10 \%$. This is unsurprising given that Rx5day is a less extreme rainfall index than Rx1day and tends to exhibit behavior more similar to the mean. As shown in Figure 5, there is almost no distinction between the $1.5^{\circ} \mathrm{C}$ and $2^{\circ} \mathrm{C}$ representative lines when considering the same experiment. However, obvious differences appear between the three experiments (LWR, RCP4.5, RCP8.5). The CESM LWR simulation rises at the highest rate, followed by RCP4.5, and RCP8.5 presents the lowest rate. The increase in the indices at high percentiles is higher in the LWR simulations than under the RCPs. This indicates that the influence might be different between transient and quasi-equilibrium simulations. ASAs are projected to experience greater relative increases in the upper tail for these indices than HAs. This suggests that ASAs may need to prepare for greater risks from extreme precipitation events under global warming.

For $1.5^{\circ} \mathrm{C}$ relative to the historical period, greater $\mathrm{PR}$ values are simulated in East-Central Asia (with PR in most regions of 1.0-1.5) (Figure 6(a)(c)(e)). There is no monotonic increase in Rx1day under a further $0.5^{\circ} \mathrm{C}$ warming. Central Asia and North India, which are projected to experience substantial increases in precipitation extremes under warming to $1.5^{\circ} \mathrm{C}$, are projected to experience slight decreases between $1.5^{\circ} \mathrm{C}$ and $2{ }^{\circ} \mathrm{C}$ global warming. This again illustrates that warming and precipitation increases are not simply positively correlated. However, most regions still show positive correlations between temperature and extreme precipitation changes (Figure 6(b)(d)(f)). The spatial pattern of Rx5day is similar to that of Rx1day but with smaller PR values (Figure 7).

\subsection{Further changes in R95p}

In general, the higher the extreme precipitation proportion, the greater the 
probability risks. Figure 8 provides the changes in R95p as a percentage of total precipitation, and we see that the increases in magnitude exceed 10\% in HAs (Figure 8(a)). Under RCP4.5 and RCP 8.5, Southeast China and the Himalayas also experience increases in the proportion of extreme precipitation, but these are lower than those projected by the LWR. Other HAs have less obvious variation in R95p changes under the RCPs compared with the results of the LWR (Figure 8(c)(e)). Likewise, there is little change in ASAs based on the three experiments. Increasing warming by $0.5^{\circ} \mathrm{C}$ appears to be a double-edged sword that would cause some regions (Southeast China and the Himalayas) to experience increased extreme precipitation and other regions (North China and North India) to experience spatially inhomogeneous changes and perhaps even decreases (Figure 8(b)(d)(f)).

We use the R95p annual days change to describe the variation intensity and R95p area fraction change for the variation range. R95p annual days means the count of total annual days that meet the definition of R95p. The R95p area fraction indicates the variation of the R95p percentage shift to positive or negative. Under the background of extreme precipitation increasing, R95p annual days in HAs increase by 10.8 days, 3.8 days, and 1.5 days in the $1.5^{\circ} \mathrm{C}$ limits and increase by 13.1 days, 8.4 days, and 4.2 days in the $2^{\circ} \mathrm{C}$ limits according to LWR, RCP4.5 and RCP8.5, respectively. Coincident with spatial pattern changes, the annual day variation in ASAs is not obvious (Table S1). From the perspective of the R95p area fraction, R95p in most of $\mathrm{HAs}$ is projected to see increases both under the $1.5^{\circ} \mathrm{C}$ and the $2{ }^{\circ} \mathrm{C}$ warming limits. In contrast, only half of ASAs are expected to witness more R95p, and the proportion of R95p in ASAs increases only slightly under $0.5^{\circ} \mathrm{C}$ further warming (Table S2). 


\section{The mechanisms and uncertainty of the results}

From the CESM model's extreme precipitation prediction results, we can conclude that along with the mean temperature increase, the extreme precipitation response is uneven in different areas. In the $1.5^{\circ} \mathrm{C}$ and $2^{\circ} \mathrm{C}$ warming future, ASAs will tend to experience a greater mean temperature increase than HAs due to the differences in vegetation cover, types of clouds and anthropogenic aerosols (Huang et al., 2017). The lower vegetation cover in ASAs leads to lower transpiration rates, resulting in higher surface air temperatures. The thick low clouds in HAs can effectively reflect shortwave sunlight, and their low cloud tops result in limited longwave warming effects. In contrast, most cirrus clouds in ASAs reflect less sunlight to the top atmosphere but absorb more atmospheric counter radiation, leading to a sharp regional temperature increase. Moreover, anthropogenic aerosols, which are likely to cool down the surface, are less abundant in ASAs than in HAs. Thus, due to the intensifying warming effect, the ASAs will bear higher extreme precipitation event risks, and the extreme precipitation percentage variation changes in most ASAs are projected to be higher than those in the HAs. For the hydrologic cycle, HAs are likely to witness more increases in moisture convergence and then more total precipitation, while the moisture divergence in ASAs is anomalous (Zhang et al., 2019). More base precipitation and moisture convergence in the warmer world drive HAs to experience more total extreme precipitation increases.

The CESM is released by NCAR and consists of several component models and a coupler. Each module is independent, and modules are connected by a coupler (Kay et al., 2015). Although that design may reduce model errors as much as possible, it still has some internal errors that are hard to eliminate because of the simulation deviation of the model from the actual atmospheric motion state and errors in coupling. Moreover, some physical processes, parameterized schemes and dynamic frameworks must be constantly improved. The CESM LWR begins from a slightly different initial atmospheric state (created by randomly perturbing temperatures at the level of round-off error). However, there are still some differences among those runs 
319 considering extreme precipitation indices. RCP4.5 and RCP8.5 are transient scenarios, 320 and the response to $1.5^{\circ} \mathrm{C}$ or $2^{\circ} \mathrm{C}$ warming limits is not in equilibrium. This will result 321 in some overestimation of the temperature increase and cause some related influence, 322 as mentioned in the model data. Despite these problems, the CESM three special runs 323 used in our paper reveal that extreme precipitation will increase regardless of intensity 324 or occurrence under the background of global warming in the future. This is in line 325 with most other climate models and our knowledge. To better understand the reason 326 for these uneven changes and their underlying physical mechanisms, more specific 327 global and regional climate models need to be tested in further studies. 


\section{Summary and Conclusions}

We utilized four climate prediction experiments from CESM to investigate changes in extreme precipitation under the $1.5^{\circ} \mathrm{C}$ and $2^{\circ} \mathrm{C}$ global warming limits over East-Central Asia. Under the $1.5^{\circ} \mathrm{C}$ warming limits, extreme precipitation is projected to increase in almost all regions, especially in Southeast China and the Himalayas. With a further $0.5^{\circ} \mathrm{C}$ warming, most regions are projected to experience a further increase in extreme precipitation, although it is not a linear increase. Overall, there will be more extreme precipitation over East-Central Asia under global warming.

According to the LWR, Southeast China and the Himalayas will witness over 2 $\mathrm{mm}$ and $6 \mathrm{~mm}$ increases in Rx1day and $\mathrm{Rx} 5$ day in the $1.5^{\circ} \mathrm{C}$ warming future, respectively. However, RCP4.5 and RCP8.5 suggest only a slight increase (perhaps due to a difference between transient and quasi-equilibrium responses). For the $2^{\circ} \mathrm{C}$ limit relative to $1.5^{\circ} \mathrm{C}$, the response of HAs to temperature rise is almost positive, while some ASAs, such as North India, North China, and Northeast Mongolia, indicate a moderate decrease.

The PR of Rx1day and Rx5day will grow exponentially with increasing percentile thresholds, indicating that the most intense extreme precipitation events will occur more frequently in the warming future. It is worth mentioning that the slope of PR in ASAs will be greater than that in HAs, which means a higher relative increase in risk. Considering that ASAs are less resistant and more vulnerable to storms and floods, extreme precipitation events may cause more disasters here unless adequate adaptation plans are put in place.

There is projected to be an over 200-mm increase in the amplitude of R95p in a $1.5^{\circ} \mathrm{C}$ future and a further $100-\mathrm{mm}$ increase in $2^{\circ} \mathrm{C}$ relative to $1.5^{\circ} \mathrm{C}$ in Southeast China and the Himalayas. The proportion of R95p in total precipitation will also have a modest increase of approximately 10\%-20\% in the regions previously mentioned. Nevertheless, ASAs are expected to experience spatially inhomogeneous changes in the contribution of extreme precipitation to total precipitation. This difference is also reflected in the changes in R95p annual days and the percentage of 
357 R95p area. Approximately a 5-day increase under $1.5^{\circ} \mathrm{C}$ and an 8-day increase under $35822^{\circ} \mathrm{C}$ are expected to appear in HAs. Half of the ASAs locations are expected to 359 experience an increase and half a decrease in R95p annual days. Likewise, only HAs 360 are expected to experience large increases in the R95p area fraction.

361 For the changes in SDII, most HAs will witness $0.4-0.8 \mathrm{~mm} /$ day (in $1.5^{\circ} \mathrm{C}$ 362 relative to the historical period) and $0.2-0.4 \mathrm{~mm} /$ day (in $2^{\circ} \mathrm{C}$ relative to $1.5^{\circ} \mathrm{C}$ ) 363 increases. North India and Pakistan are projected to experience decreases, and most 364 ASAs will see SDII increases in terms of values and percentiles. 


\section{Acknowledgements}

366 This work was jointly supported by the National Natural Science Foundation of 367 China (41705077, 41630426) and the National Key Research and Development 368 Program of China (2017YFC1502305). ADK was funded by the Australian Research 369 Council (DE180100638). The authors acknowledge the NCAR for releasing the 370 CESM low-warming experiment products and the data were acquired from 371 http://www.cesm.ucar.edu/experiments/1.5-2.0-targets.html

372 The authors thank the two anonymous reviewers for their valuable suggestions. 


\section{References}

Alexander, L. V., Zhang, X., Peterson, T. C., Caesar, J., Gleason, B., Tank, A. M. G. K., et al. (2006). Global observed changes in daily climate extremes of temperature and precipitation. Journal of Geophysical Research-Atmospheres, 111, D05109. https://doi.org/10.1029/2005JD006290

Chen, H. P., and Sun, J. Q. (2017). Contribution of human influence to increased daily precipitation extremes over China. Geophysical Research Letters, 44(5), 2436-2444. https://doi.org/ 10.1002/2016GL072439

Chen, H. P., and Sun, J. Q. (2018). Projected changes in climate extremes in China in a $1.5^{\circ} \mathrm{C}$ warmer world. International Journal of Climatology, 38(9), 3607-3617. doi: 10.1002/joc.5521

Coumou, D., and Rahmstorf, S. (2012). A decade of weather extremes. Nature Climate Change, 2, 491-496. https://doi.org/10.1038/NCLIMATE1452

Donat, M. G., Alexander, L. V., Yang, H., Durre, I., Vose, R., Dunn, R. J. H., et al. (2013). Updated analyses of temperature and precipitation extreme indices since the beginning of the twentieth century: The HadEX2 dataset. Journal of Geophysical Research-Atmospheres, 118, 2098-2118. https://doi.org/10.1002/jgrd.50150

Dosio, A., and Fischer, E. M. (2018). Will half a degree Make a difference robust projections of indices of mean and extreme climate in Europe under $1.5^{\circ} \mathrm{C}, 2^{\circ} \mathrm{C}$, and $3^{\circ} \mathrm{C}$ global warming. Geophysical Research Letters, 45, 935-944. https://doi.org/10.1002/2017GL076222

Endo, H., Kitoh, A., Mizuta, R., and Ishii, M. (2017). Future Changes in Precipitation Extremes in East Asia and Their Uncertainty Based on Large Ensemble Simulations with a High-Resolution AGCM. SOLA, 13(0), 7-12. doi:10.2151/sola.2017-002

Feng, S., and Fu, Q. (2013). Expansion of global drylands under a warming climate. Atmospheric Chemistry and Physics, 13, 10081-10094. https://doi.org/10.5194/acp-13-10081-2013

Fischer, E. M., Beyerle, U., Schleussner, C. F., King, A. D., and Knutti, R. (2018). Biased estimates of changes in climate extremes from prescribed SST simulations. Geophysical Research Letters, 45(16), 8500-8509. https://doi.org/10.1029/2018GL079176

Fischer, E. M., and Knutti, R. (2015). Anthropogenic contribution to global occurrence of heavy-precipitation and high-temperature extremes. Nature Climate Change, 5, 560-564. https://doi.org/10.1038/nclimate2617

Guan, Y. H., Zheng, F. L., Zhang, X. C., and Wang, B. (2017). Trends and variability of daily precipitation and extremes during 1960-2012 in the Yangtze River Basin, China. International Journal of Climatology, 37, 1282-1298. https://doi.org/10.1002/joc.4776

Huang, J. P., Ji, M. X., Xie, Y. K., Wang, S. S., He, Y. L., and Ran, J. J. (2016b). Global semi-arid climate change over last 60 years. Climate Dynamics, 46, 1131-1150. https://doi.org/ 10.1007/s00382-015-2636-8

Huang, J. P., Yu, H. P., Dai, A. G., Wei, Y., and Kang, L. T. (2017). Drylands face potential threat under $2^{\circ} \mathrm{C}$ global warming target. Nature Climate Change, 7(6), 417-422. https://doi.org/10.1038/NCLIMATE3275

Huang, J. P., Yu, H. P., Guan, X. D., Wang, G. Y., and Guo, R. X. (2016a). Accelerated dryland expansion under climate change. Nature Climate Change, 6(2), 166-171. https://doi.org/10.1038/NCLIMATE2837

Hurrell, J. W., Holland, M. M., Gent, P. R., Ghan, S., Kay, J. E., Kushner, P. J. et al. (2013). The 
Community Earth System Model a framework for collaborative research. Bulletin of the American Meteorological Society, 94, 1339-1360. https://doi.org/10.1175/BAMS-D-12-00121.1

Karl, T. R., Nicholls, N., and Ghazi, A. (1999). CLIVAR/GCOS/WMO workshop on indices and indicators for climate extremes: Workshop summary. Climatic Change, 42, 3-7. https://doi.org/ 10.1023/A:1005491526870

Kay, J. E., Deser, C., Phillips, A., Mai, A., Hannay, C., Strand, G. et al. (2015). The community earth system model (CESM) large ensemble project:A community resource for studying climate change in the presence of internal climate variability. Bulletin of the American Meteorological Society, 96, 1333-1349. https://doi.org/10.1175/BAMS-D-13-00255.1

Kharin, V. V., Zwiers, F. W., Zhang, X., and Wehner, M. (2013). Changes in temperature and precipitation extremes in the CMIP5 ensemble. Climatic Change, 119, 345-357. https://doi.org/10.1007/s10584-013-0705-8

King, A. D., Karoly, D. J., and Henley, B. J. (2017). Australian climate extremes at $1.5^{\circ} \mathrm{C}$ and $2^{\circ} \mathrm{C}$ of global warming. Nature Climate Change, 7(6), 412-416. https://doi.org/10.1038/NCLIMATE3296

King, A. D., Knutti, R., Uhe, P., Mitchell, D. M., Lewis, S. C., Arblaster, J. M., and Freychet, N. (2018). On the linearity of local and regional temperature changes from $1.5^{\circ} \mathrm{C}$ to $2^{\circ} \mathrm{C}$ of global warming. Journal of Climate, 31(18), 7495-7514. https://doi.org/10.1175/JCLI-D-17-0649.1

Kusunoki, S. (2017). Future changes in precipitation over East Asia projected by the global atmospheric model MRI-AGCM3.2. Climate Dynamics, 51, 4601-4617. https://doi.org/10.1007/s00382-016-3499-3

Li, D. H., Zhou, T. J., Zou, L. W., Zhang, W. X., and Zhang, L. X. (2018). Extreme high-temperature events over East Asia in $1.5^{\circ} \mathrm{C}$ and $2^{\circ} \mathrm{C}$ warmer futures analysis of NCAR CESM low-warming experiments. Geophysical Research Letters, 45, 1541-1550. https://doi.org/10.1002/2017GL076753

Li, Q., Zhang, R. H., and Wang, Y. (2016). Interannual variation of the wintertime fog-haze days across central and eastern China and its relation with East Asian winter monsoon. International Journal of Climatology, 36, 346-354. https://doi.org/10.1002/joc.4350

Lin, L., Wang, Z. L., Xu, Y. Y., and Fu, Q. (2016). Sensitivity of precipitation extremes to radiative forcing of greenhouse gases and aerosols. Geophysical Research Letters, 43(18), 9860-9868. https://doi.org/10.1002/2016GL070869

Lin, L., Wang, Z. L., Xu, Y. Y., Zhang, X. Y., Zhang, H., and Dong, W. J. (2018). Additional intensification of seasonal heat and flooding extreme over China in a $2^{\circ} \mathrm{C}$ warmer world compared to $1.5^{\circ} \mathrm{C}$. Earths Future, 6(7), 968-978. https://doi.org/10.1029/2018EF000862

Middleton, N. J., and Thomas, D. S. G. (1997). World atlas of desertification, 2ndedn. Arnold, a member of the Hodder Headline Group, London.

Mitchell, D., Heaviside, C., Vardoulakis, S., Huntingford, C., Masato, G. Guillod, B. P. et al. (2016). Attributing human mortality during extreme heat waves to anthropogenic climate change. Environmental Research Letters, 11(7), 074006. https://doi.org/10.1088/1748-9326/11/7/074006

Orlowsky, B., and Seneviratne, S. I. (2012). Global changes in extreme events: regional and seasonal dimension. Climatic Change, 110, 669-696. doi: 10.1007/s10584-011-0122-9

Perkins, S. E., and Alexander, L. V. (2013). On the measurement of heat waves. Journal of 
Climate, 26, 4500-4517. https://doi.org/10.1175/JCLI-D-12-00383.1

Perkins, S. E., Alexander, L. V., and Nairn, J. R. (2012). Increasing frequency, intensity and duration of observed global heatwaves and warm spells. Geophysical Research Letters, 39, L20714. https://doi.org/10.1029/2012GL053361

Peterson, T. C. et al. Report on the Activities of the Working Group on Climate Change Detection and Related Rapporteurs 1998-2001. WMO, Rep. WCDMP-47, WMO-TD 1071, Geneve, Switzerland, 143pp.

Ren, G. Y., and Zhou, Y. Q. (2014). Urbanization effect on trends of extreme temperature indices of national stations over mainland China, 1961-2008. Journal of Climate, 27, 2340-2360. https://doi.org/10.1175/JCLI-D-13-00393.1

Sanderson, B. M., O'Neill, B., and Tebaldi, C. (2016). What would it take to achieve the Paris temperature targets? Geophysical Research Letters, 43, 7133-7142. https://doi.org/10.1002/2016GL069563

Sanderson, B. M., Xu, Y. Y., Tebaldi, C., Wehner, M., O'Neill, B., Jahn, A. et al. (2017). Community climate simulations to assess avoided impacts in $1.5^{\circ} \mathrm{C}$ and $2^{\circ} \mathrm{C}$ futures. Earth System Dynamics, 8, 827-847. https://doi.org/10.5194/esd-8-827-2017

Scheff, J., and Frierson, D. M. W. (2014). Scaling potential evapotranspiration with greenhouse warming. Journal of Climate, 27, 1539-1558. https://doi.org/10.1175/JCLI-D-13-00233.1

Scherrer, S. C., Fischer, E. M., Posselt, R., Liniger, M. A., Croci-Maspoli, M., and Knutti, R. (2016). Emerging trends in heavy precipitation and hot temperature extremes in Switzerland. Journal of Geophysical Research-Atmospheres, 121, 2626-2637. https://doi.org/10.1002/2015JD024634

Schleussner, C. F., Lissner, T. K., Fischer, E. M., Wohland, J., Perrette, M., Golly, A. et al. (2016). Differential climate impacts for policy-relevant limits to global warming: the case of $1.5^{\circ} \mathrm{C}$ and $2^{\circ}$ C. Earth System Dynamics, 7(2), 327-351. https://doi.org/10.5194/esd-7-327-2016

Sillmann, J., Kharin, V. V., Zhang, X., Zwiers, F. W., and Bronaugh, D. (2013a). Climate extremes indices in the CMIP5 multimodel ensemble: Part 1. Model evaluation in the present climate. Journal of Geophysical Research-Atmospheres, 118, 1716-1733. https://doi.org/10.1002/jgrd.50203

Sillmann, J., Kharin,V. V., Zhang, X., Zwiers, F. W., and Bronaugh, D. (2013b). Climate extremes indices in the CMIP5 multimodel ensemble: Part 2. Future climate projections. Journal of Geophysical Research-Atmospheres, 118, 2473-2493. https://doi.org/10.1002/jgrd.50188

Stone, D. A., and Allen, M. R. (2005), The end-to-end attribution problem: From emissions to impacts. Climatic Change, 71, 303-318. https://doi.org/10.1007/s10584-005-6778-2

Wang, Z. L., Lin, L., Zhang, X. Y., Zhang, H., Liu, L. K., and Xu, Y. Y. (2017). Scenario dependence of future changes in climate extremes under $1.5^{\circ} \mathrm{C}$ and $2{ }^{\circ} \mathrm{C}$ global warming. Scientific Reports, 7, 46432. https://doi.org/10.1038/srep46432

Wei, Y., Yu, H. P., Huang, J. P., Zhou, T. J., Zhang, M., and Ren, Y. (2019). Drylands climate response to transient and stabilized $2^{\circ} \mathrm{C}$ and $1.5^{\circ} \mathrm{C}$ global warming targets: Climate Dynamics, 53(3-4), 2375-2389.

Xing, W., Wang, B., and Yim, S. Y. (2016). Peak-summer East Asian rainfall predictability and prediction part I: Southeast Asia. Climate Dynamics, 47, 1-13. https://doi.org/10.1007/s00382-014-2385-0

Yang, L., Villarini, G., Smith, J. A., Tian, F. Q., and Hu, H. P. (2013). Changes in seasonal 
maximum daily precipitation in China over the period 1961-2006. International Journal of Climatology, 33, 1646-1657. https://doi.org/10.1002/joc.3539

Zhai, P. M., Zhang, X. B., Wan, H., and Pan, X. H. (2005). Trends in total precipitation and frequency of daily precipitation extremes over China. Journal of Climate, 18, 1096-1108. https://doi.org/10.1175/JCLI-3318.1

Zhang, M., Yu, H. P., Huang, J. P., Wei, Y., Liu, X. Y., and Zhang, T. H. (2019). Comparison of extreme temperature response to $0.5^{\circ} \mathrm{C}$ additional warming between dry and humid regions over East-Central Asia. International Journal of Climatology, 39, 3348-3364. https://doi.org/10.1002/joc.6025

Zhang, W. X., Zhou, T. J., Zou, L. W., Zhang, L. X., and Chen, X. L. (2018). Reduced exposure to extreme precipitation from $0.5^{\circ} \mathrm{C}$ less warming in global land monsoon regions. Nature Communications, 9, 3153. https://doi.org/10.1038/s41467-018-05633-3

Zhang, W., Zhou, T., Zhang, L., and Zou, L. (2019). Future intensification of the water cycle with an enhanced annual cycle over global land monsoon regions. Journal of Climate, 32, 5437-5452. https://doi.org/10.1175/jcli-d-18-0628.1

Zhao, G. J., Huang, G., Wu, R. G., Tao, W. C., Gong, H. N., Qu, X., and Hu, K. M. (2015). A new upper-level circulation index for the East Asian summer monsoon variability. Journal of Climate, 28(24), 9977-9996. https://doi.org/10.1175/JCLI-D-15-0272.1

Zhou, S. J., Huang, G., and Huang, P. (2018). Changes in the East Asian summer monsoon rainfall under global warming: moisture budget decompositions and the sources of uncertainty. Climate Dynamics, 51(4), 1363-1373. https://doi.org/10.1007/s00382-017-3959-4

Zhou, T. J., and Chen, X. L. (2015). Uncertainty in the $2{ }^{\circ} \mathrm{C}$ warming threshold related to climate sensitivity and climate feedback. Journal of Meteorological Research, 29(6), 884-895. https://doi.org/10.1007/s13351015-5036-4 
Figure 1. Spatial changes in $\mathrm{Rx} 1$ day $(\mathrm{mm})$ in the $1.5^{\circ} \mathrm{C}$ limits relative to (minus, the same below) the historical period for (a) 1pt5, (c) RCP4.5, (e) RCP8.5. All the same but for $2^{\circ} \mathrm{C}$ relative to $1.5^{\circ} \mathrm{C}$ in (b) $2 \mathrm{pt}$, (d) RCP4.5, (f) RCP8.5. The black dotted parts represent ASAs. The red dotted parts represent the changes passing a 95\% significance test.

Figure 2. The same as Figure 1, but for Rx5day (mm).

Figure 3. The same as Figure 1, but for R95p (mm).

Figure 4. The same as Figure 1, but for SDII (mm/day).

Figure 5. (a) PR values in Rx1day in ASAs under $2^{\circ} \mathrm{C}$ and $1.5^{\circ} \mathrm{C}$ limits relative to the historical period. The x-axis represents the percentile thresholds based on the historical period. The method is as follows: First, we calculate the Rx1day in the historical period (average of 30 years) and under the $1.5^{\circ} \mathrm{C}$ warming condition in each grid point and obtain two three-dimensional arrays (month, latitude, longitude), both of which are $12,47,73$, respectively. Then, we calculate PR values using the two arrays in each grid point and set grid points in humid areas as missing values. After that, we convert this new three-dimensional array of PR into a one-dimensional array in ascending sequence. Finally, we set the percentile thresholds and draw the figures. (b), (c), and (d) are the same as (a) but represent Rx1day in HAs, Rx5day in ASAs, and Rx5day in HAs, respectively.

Figure 6. PR spatial changes in $\mathrm{Rx} 1$ day in the $1.5^{\circ} \mathrm{C}$ limits relative to the historical period for (a) $1 \mathrm{pt5}$, (c) RCP4.5, (e) RCP8.5. All the same but for $2^{\circ} \mathrm{C}$ relative to $1.5^{\circ} \mathrm{C}$ in (b) 2pt, (d) RCP4.5, (f) RCP8.5. The black dotted parts represent ASAs. The red dotted parts represent the changes passing a 95\% significance test.

Figure 7. The same as Figure 6, but for Rx5day.

Figure 8. Spatial changes in R95p as a percentage of total precipitation in the $1.5^{\circ} \mathrm{C}$ limits relative to the historical period for (a) 1pt5, (c) RCP4.5, (e) RCP8.5. All the same but for $2^{\circ} \mathrm{C}$ relative to $1.5^{\circ} \mathrm{C}$ for (b) $2 \mathrm{pt}$, (d) $\mathrm{RCP} 4.5$, (f) RCP8.5. The black dotted parts represent ASAs. The red dotted parts represent the changes passing a $95 \%$ significance test. 

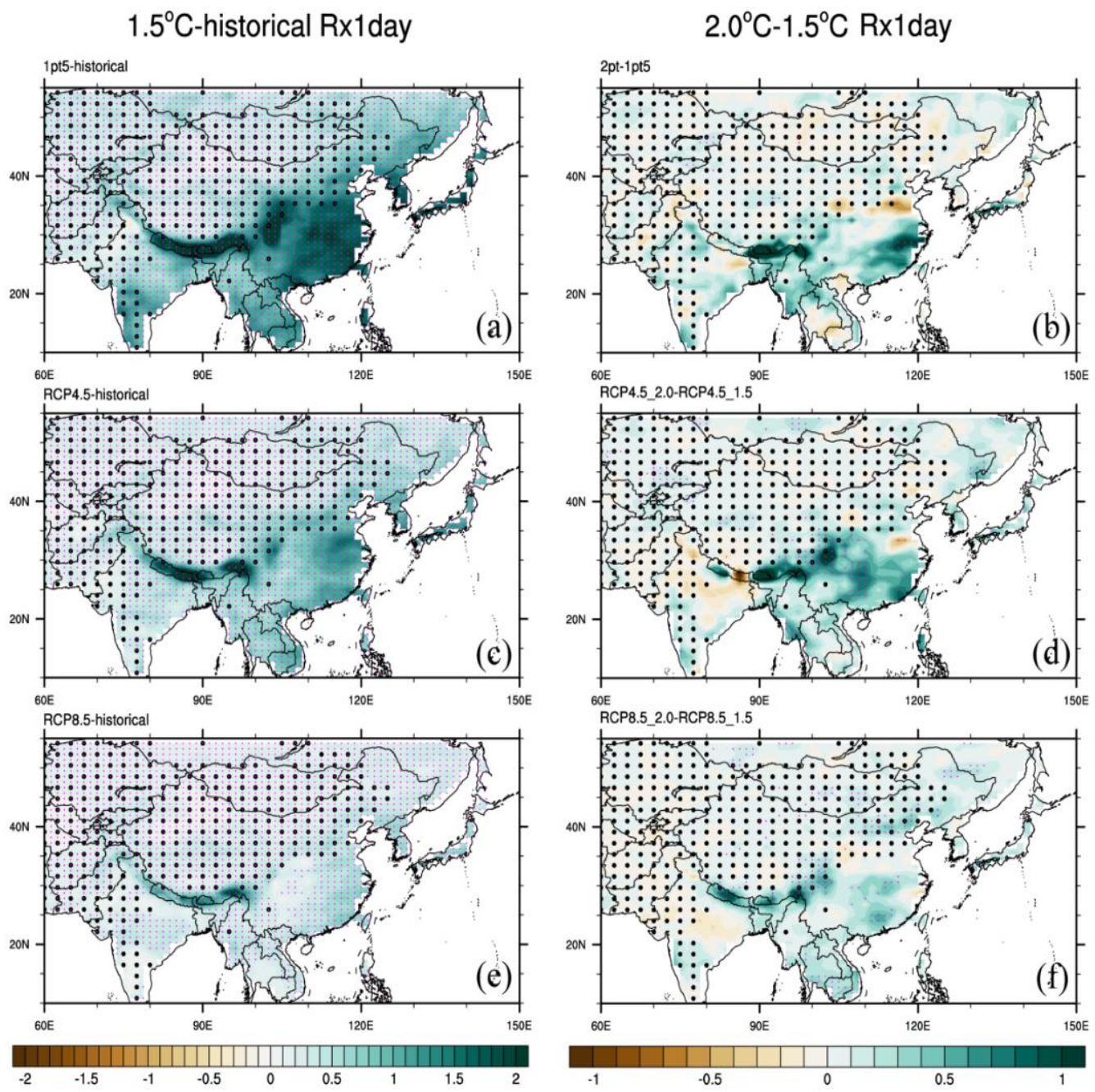

Figure 1. Spatial changes in $\mathrm{Rx} 1$ day $(\mathrm{mm})$ in the $1.5^{\circ} \mathrm{C}$ limits relative to (minus, the

559 same below) the historical period for (a) 1pt5, (c) RCP4.5, (e) RCP8.5. All the same

560 but for $2^{\circ} \mathrm{C}$ relative to $1.5^{\circ} \mathrm{C}$ in (b) $2 \mathrm{pt}$, (d) RCP4.5, (f) RCP8.5. The black dotted

561 parts represent ASAs. The red dotted parts represent the changes passing a 95\%

562 significance test. 

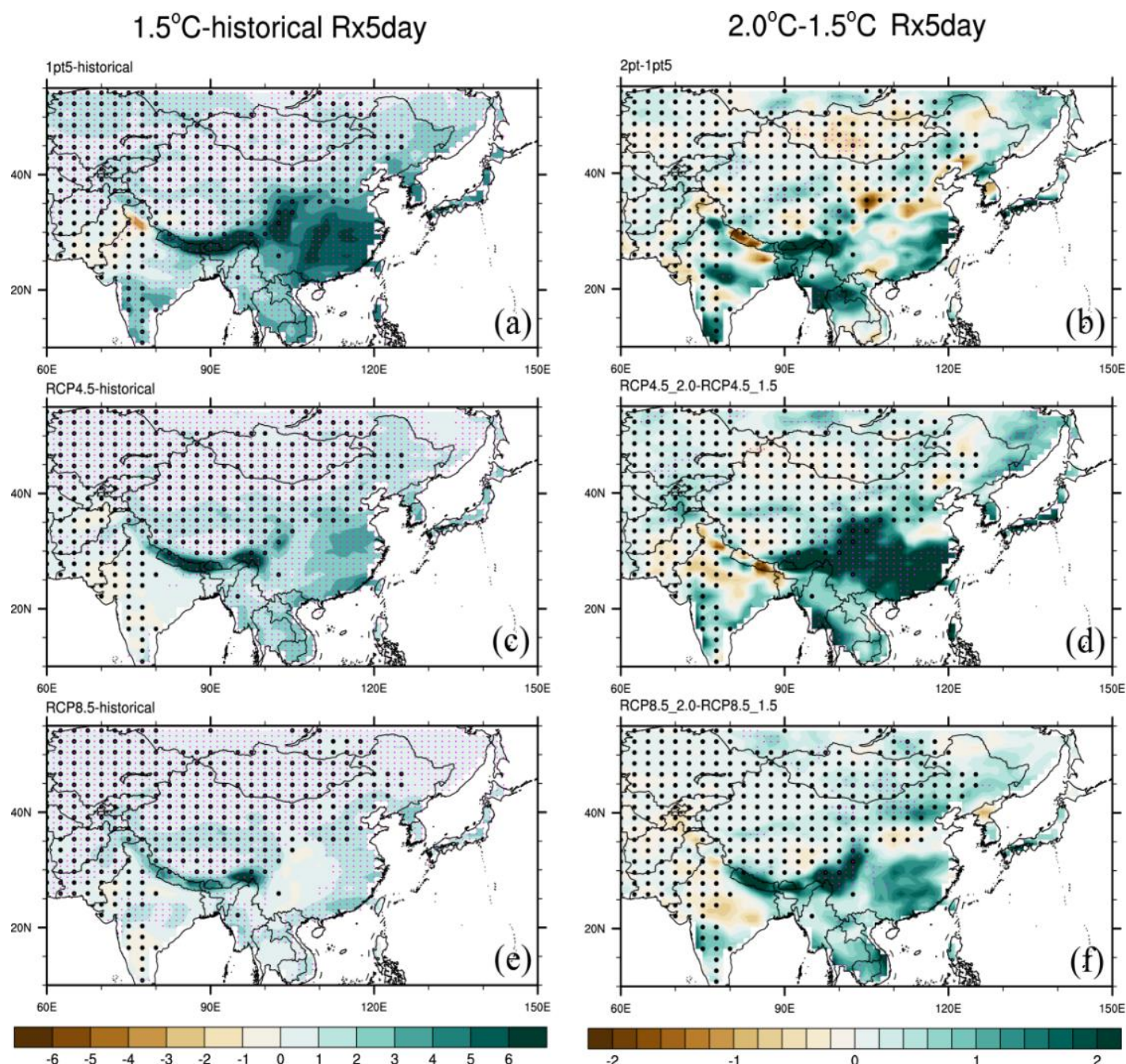

563

Figure 2. The same as Figure 1, but for Rx5day (mm). 

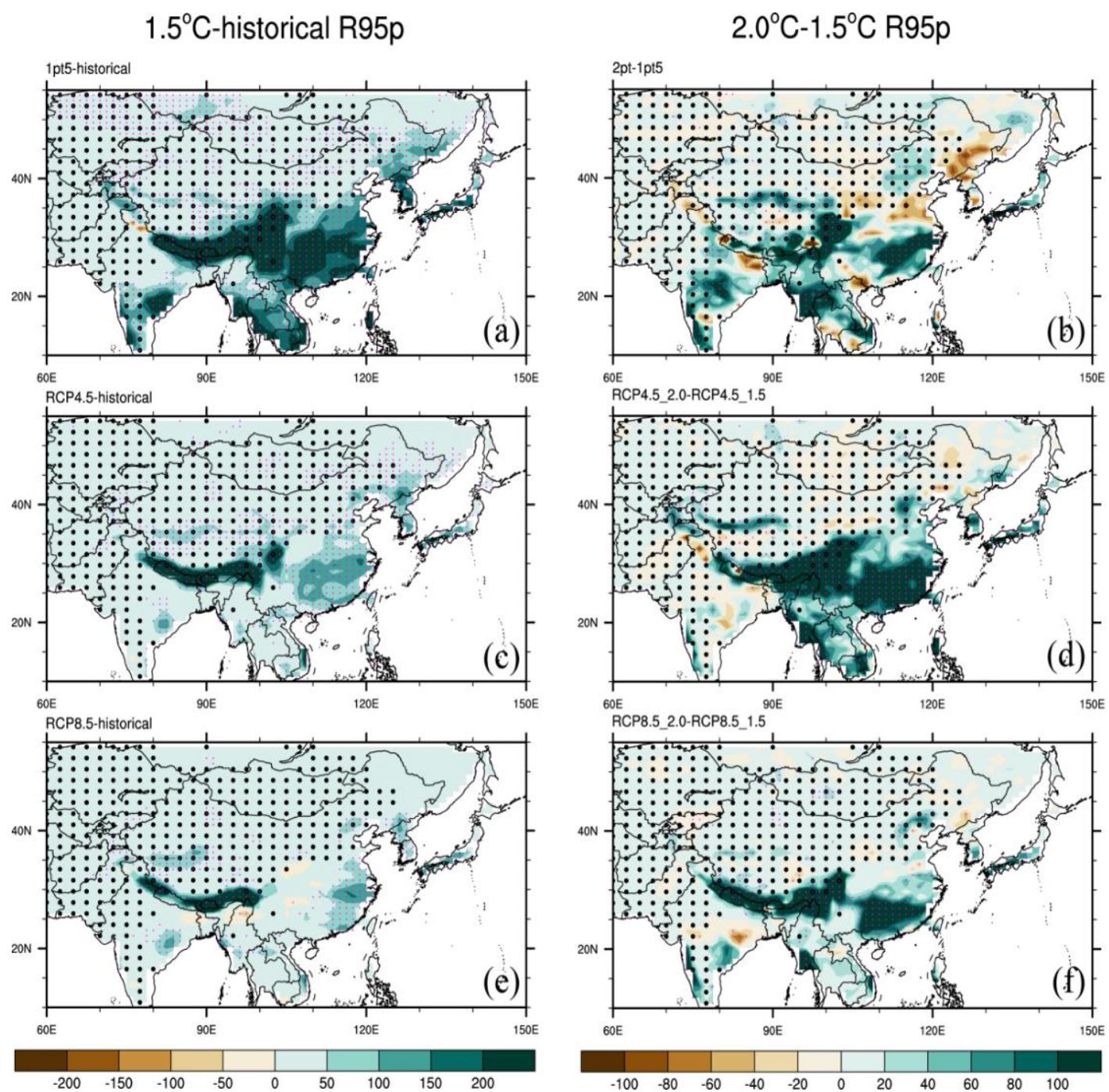

Figure 3. The same as Figure 1, but for R95p (mm). 
$1.5^{\circ} \mathrm{C}$-historical SDII
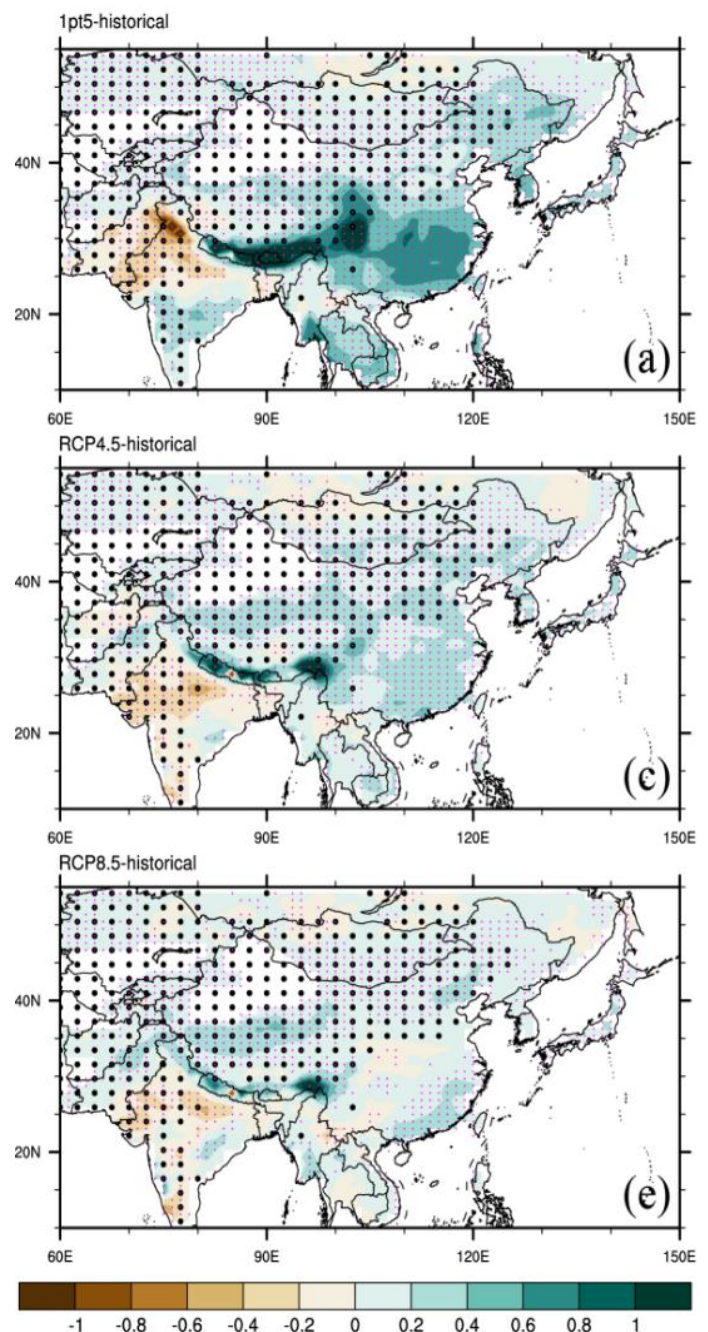

$2.0^{\circ} \mathrm{C}-1.5^{\circ} \mathrm{C} \mathrm{SDII}$
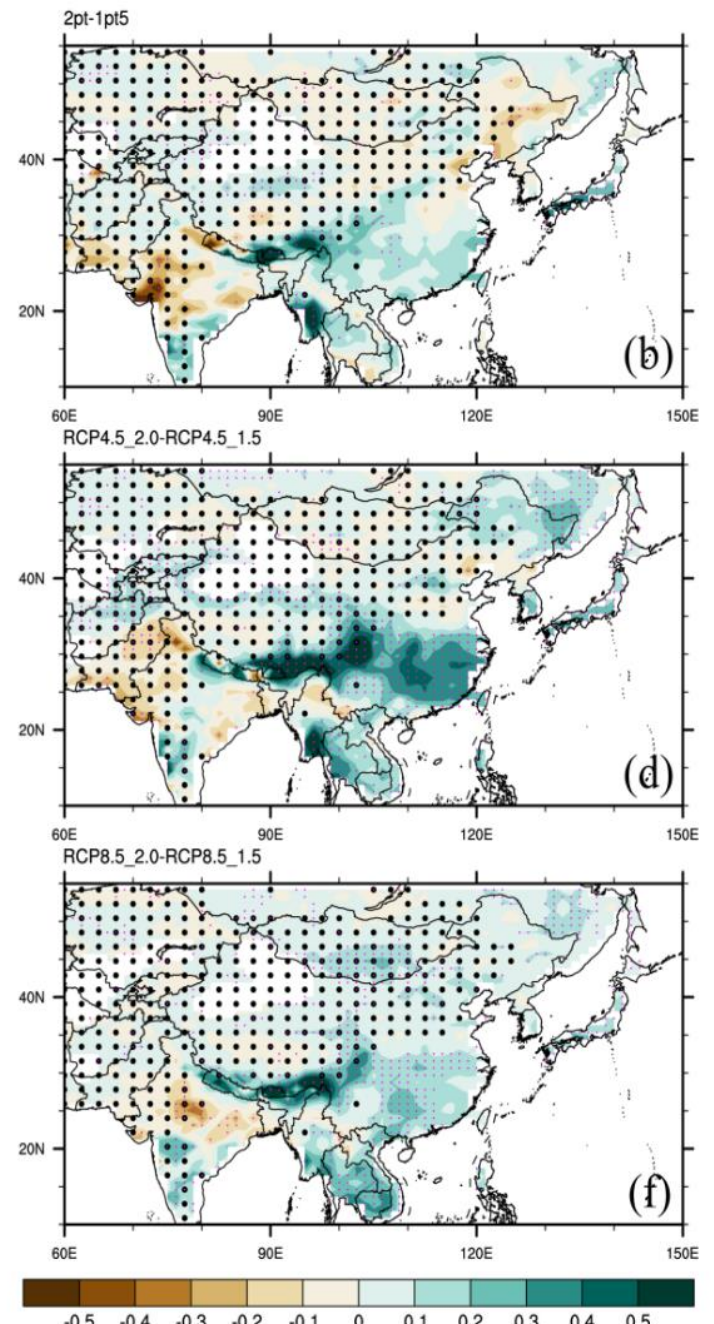

Figure 4. The same as Figure 1, but for SDII (mm/day). 

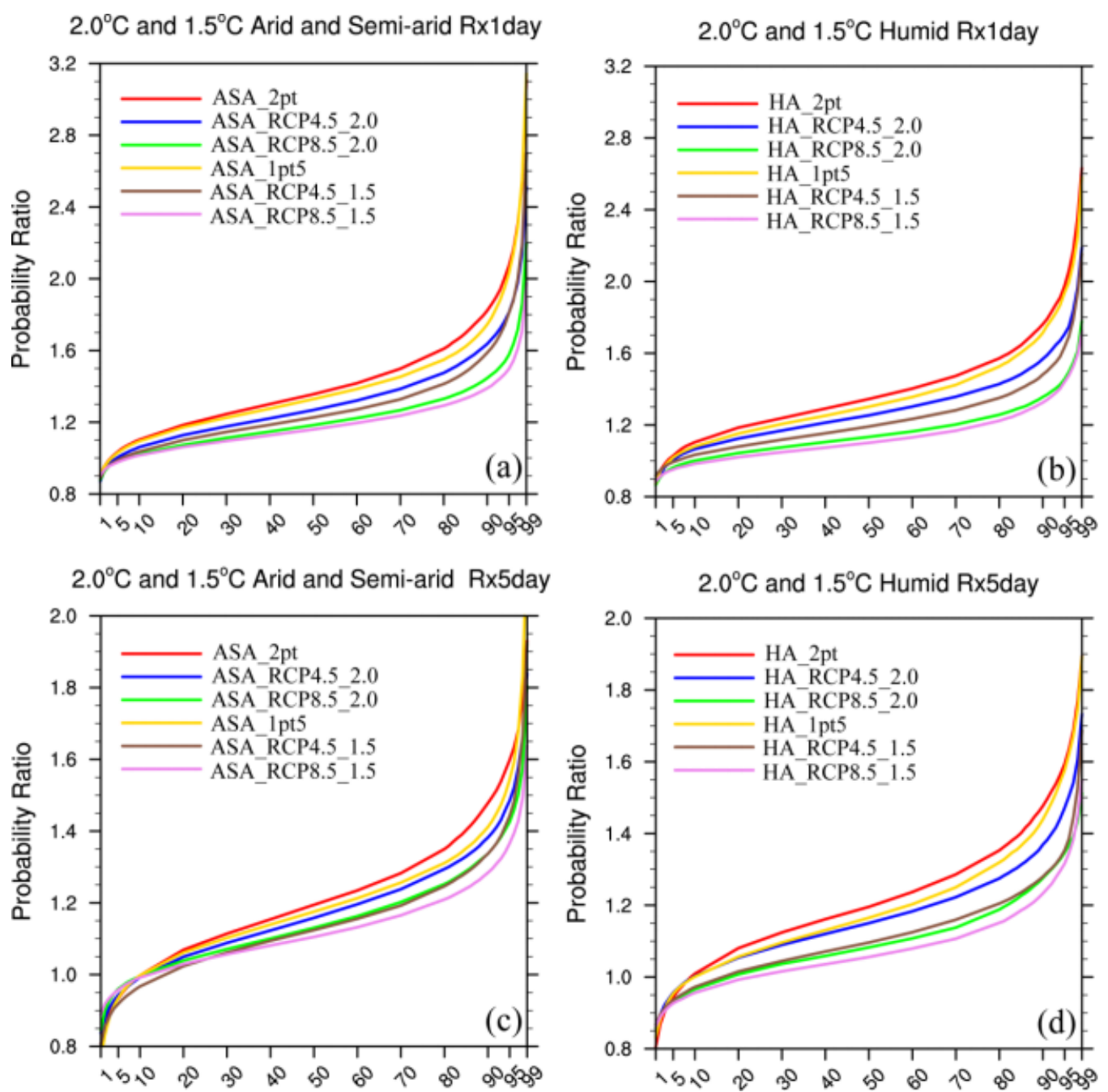

Figure 5. (a) PR values in Rx1day in ASAs under $2{ }^{\circ} \mathrm{C}$ and $1.5^{\circ} \mathrm{C}$ limits relative to the historical period. The $\mathrm{x}$-axis represents the percentile thresholds based on the historical period. The method is as follows: First, we calculate the Rx1day in the historical period (average of 30 years) and under the $1.5^{\circ} \mathrm{C}$ warming condition in each grid point and obtain two three-dimensional arrays (month, latitude, longitude), both of which are $12,47,73$, respectively. Then, we calculate PR values using the two arrays in each grid point and set grid points in humid areas as missing values. After that, we convert this new three-dimensional array of PR into a one-dimensional array in ascending sequence. Finally, we set the percentile thresholds and draw the figures. (b), (c), and (d) are the same as (a) but represent Rx1day in HAs, Rx5day in ASAs, and Rx5day in HAs, respectively. 

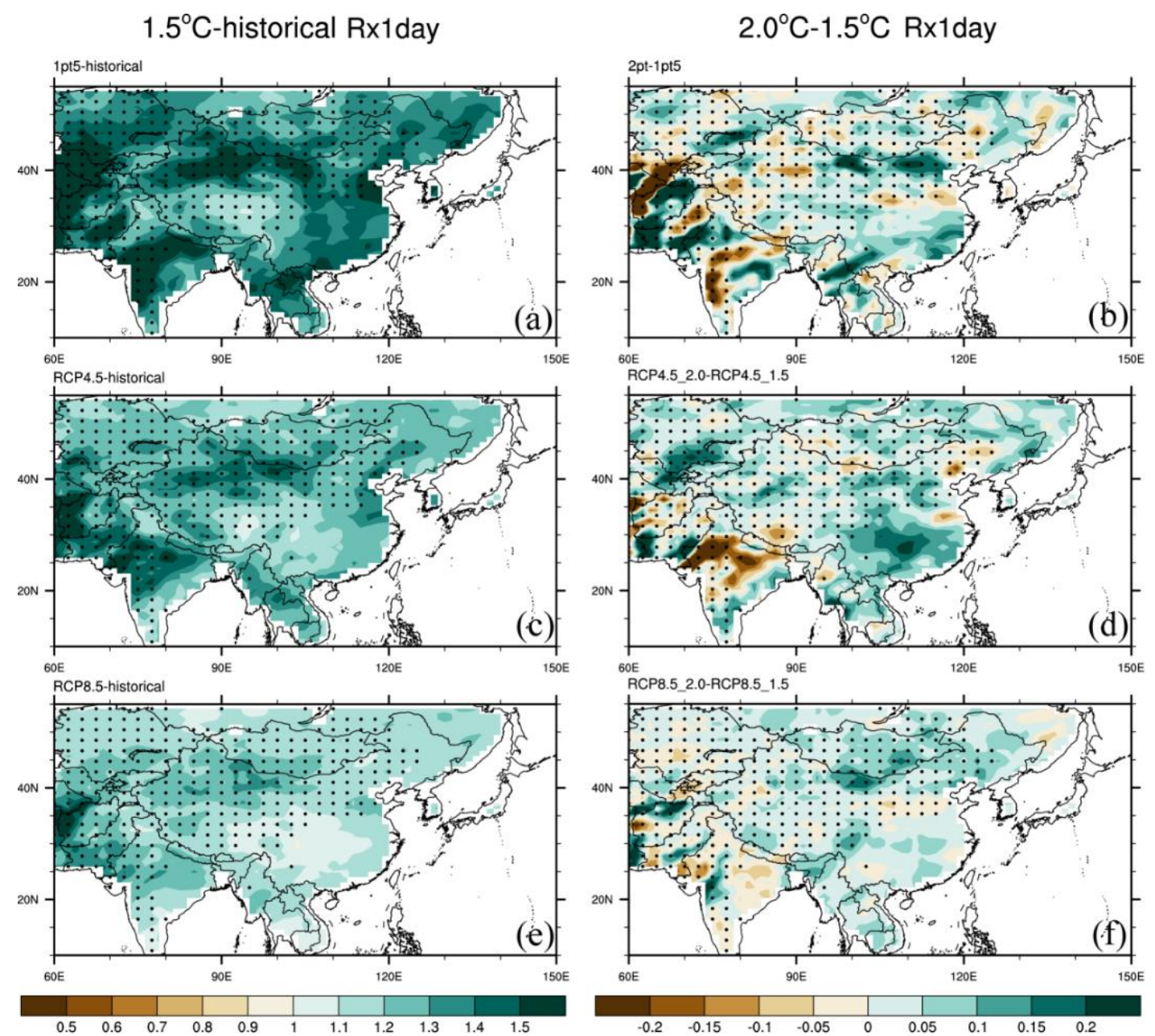

less likely | more likely

Figure 6. PR spatial changes in $\mathrm{Rx} 1$ day in the $1.5^{\circ} \mathrm{C}$ limits relative to the historical period for (a) $1 \mathrm{pt} 5$, (c) $\mathrm{RCP} 4.5$, (e) RCP8.5. All the same but for $2^{\circ} \mathrm{C}$ relative to $1.5^{\circ} \mathrm{C}$ in (b) 2pt, (d) RCP4.5, (f) RCP8.5. The black dotted parts represent ASAs. The red dotted parts represent the changes passing a 95\% significance test. 
$1.5^{\circ} \mathrm{C}$-historical Rx5day
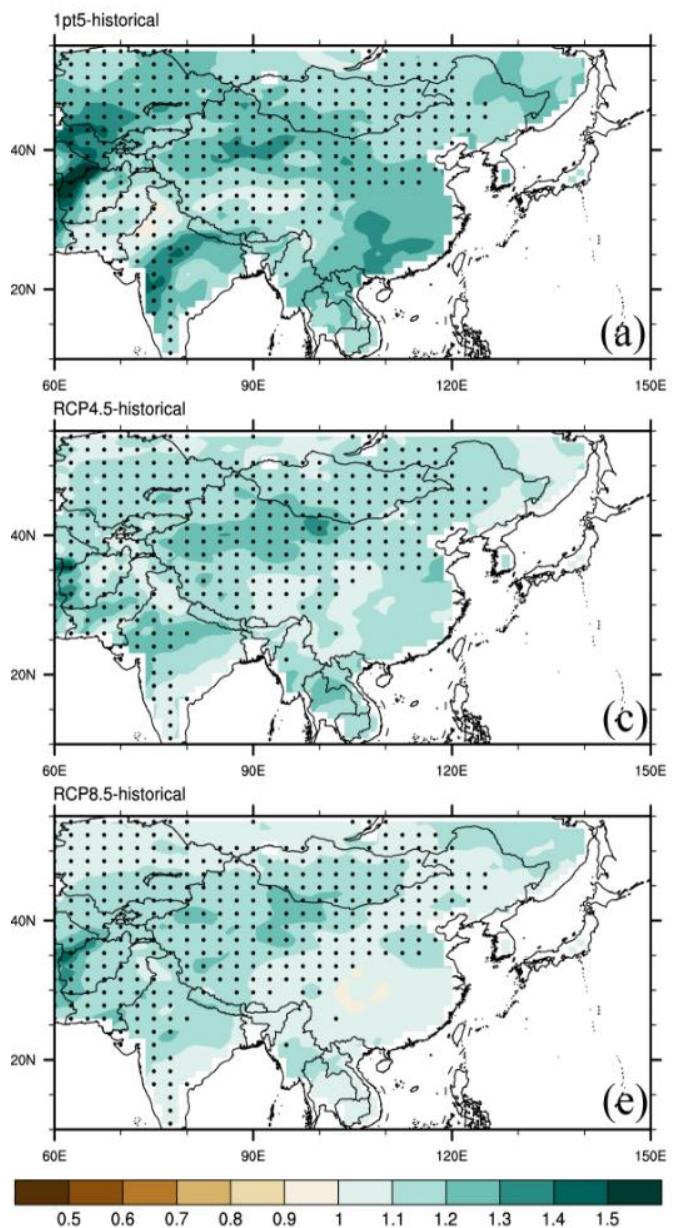

less likely | more likely $2.0^{\circ} \mathrm{C}-1.5^{\circ} \mathrm{C}$ Rx5day
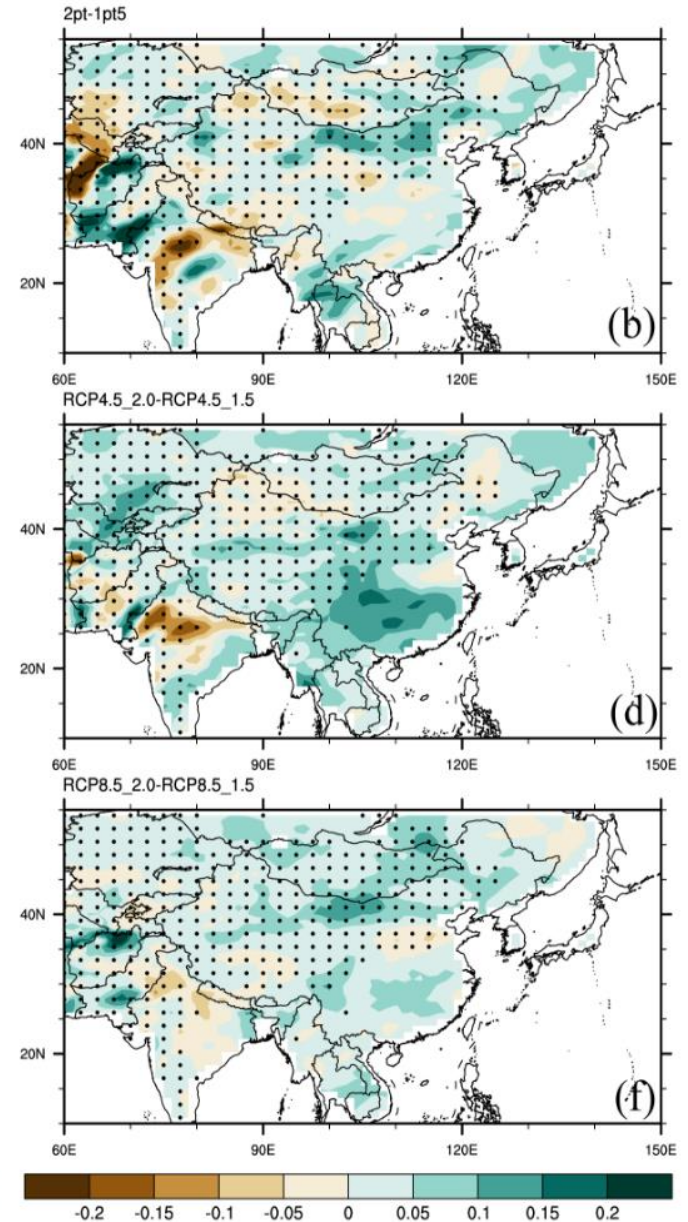

less likely | more likely

Figure 7. The same as Figure 6, but for Rx5day. 
$1.5^{\circ} \mathrm{C}$-historical R95p percent
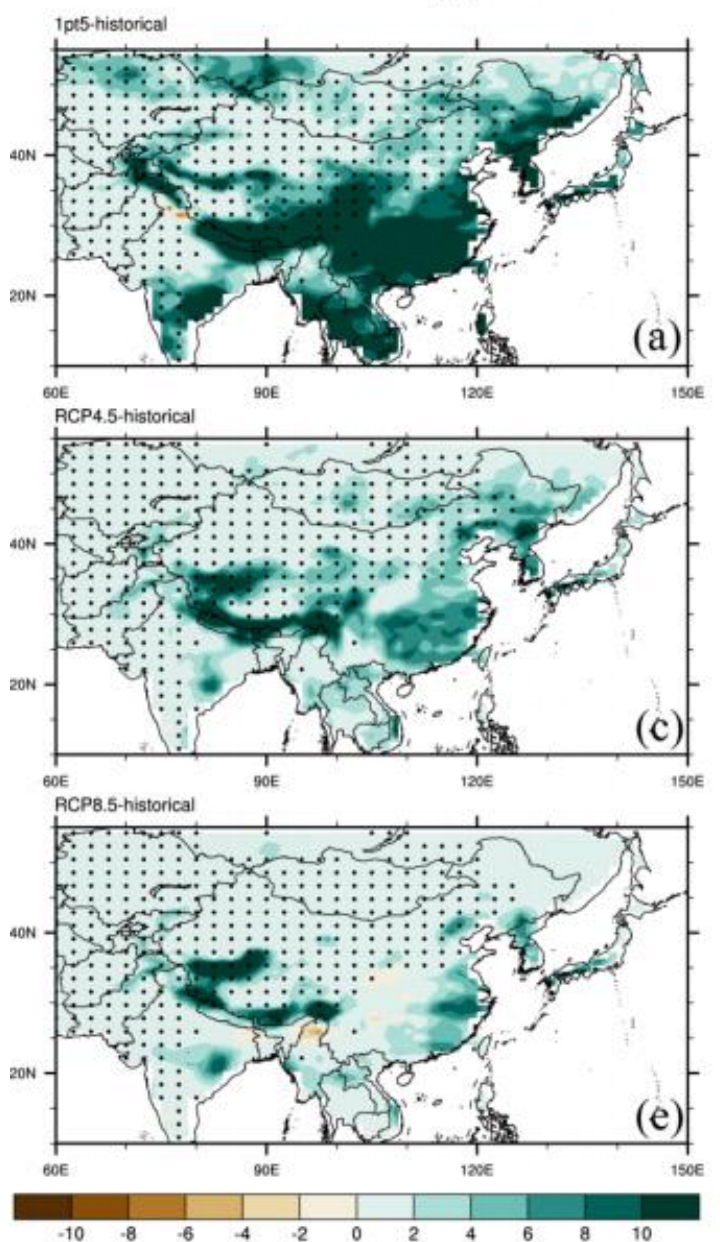

$2.0^{\circ} \mathrm{C}-1.5^{\circ} \mathrm{C}$ R95p percent
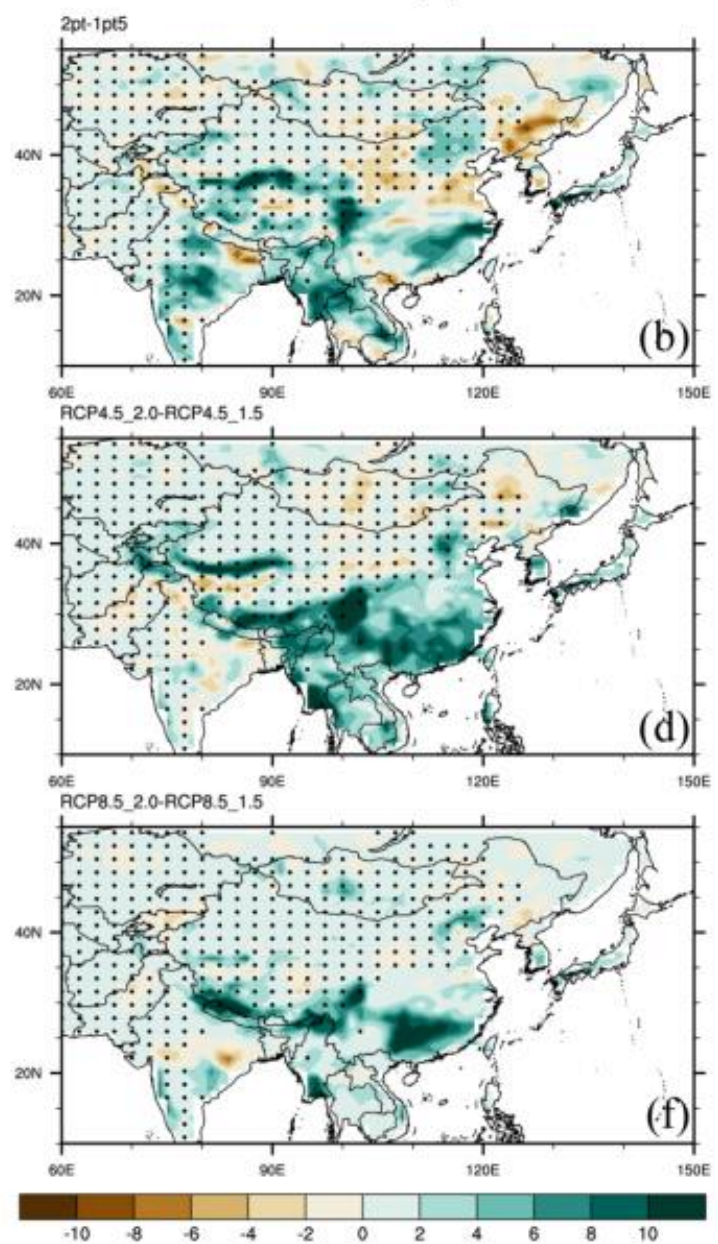

588

589

590

591

592

593

Percentage $(\%)$

Figure 8. Spatial changes in R95p as a percentage of total precipitation in the $1.5^{\circ} \mathrm{C}$ limits relative to the historical period for (a) 1pt5, (c) RCP4.5, (e) RCP8.5. All the same but for $2^{\circ} \mathrm{C}$ relative to $1.5^{\circ} \mathrm{C}$ for (b) $2 \mathrm{pt}$, (d) RCP4.5, (f) RCP8.5. The black dotted parts represent ASAs. The red dotted parts represent the changes passing a 95\% significance test. 
Reviewers' comments:

Reviewer 2: Comments to the Author

The manuscript has been substantially improved. Authors have also addressed the comments well, and in a clear manner. I would suggest publication of the paper. However, several minor issues still need to be resolved.

We are very grateful for the positive reviews of the manuscript and the detailed advice with constructive comments, which helped us to improve the article significantly. We accept all the proposed suggestions. Following these suggestions, we have revised the manuscript extensively, all the issues have been addressed. The description of $1.5^{\circ} \mathrm{C}$ and $2^{\circ} \mathrm{C}$ warming limits in Section 2.1 has been modified. All the writing mistakes raised by Reviewer \#2 has been revised one-by-one. Besides, the English of whole manuscript has been edited by Springer Nature English Language Editting (Order ID KXBTQZK5). Please find all the corrections in the revised manuscript with tracked changes. 


\section{References}

Alexander, L. V., Zhang, X., Peterson, T. C., Caesar, J., Gleason, B., Tank, A. M. G. K., et al. (2006). Global observed changes in daily climate extremes of temperature and precipitation. Journal of Geophysical Research-Atmospheres, 111, D05109. https://doi.org/10.1029/2005JD006290

Chen, H. P., and Sun, J. Q. (2017). Contribution of human influence to increased daily precipitation extremes over China. Geophysical Research Letters, 44(5), 2436-2444. https://doi.org/ 10.1002/2016GL072439

Chen, H. P., and Sun, J. Q. (2018). Projected changes in climate extremes in China in a $1.5^{\circ} \mathrm{C}$ warmer world. International Journal of Climatology, 38(9), 3607-3617. doi: 10.1002/joc.5521

Coumou, D., and Rahmstorf, S. (2012). A decade of weather extremes. Nature Climate Change, 2, 491-496. https://doi.org/10.1038/NCLIMATE1452

Donat, M. G., Alexander, L. V., Yang, H., Durre, I., Vose, R., Dunn, R. J. H., et al. (2013). Updated analyses of temperature and precipitation extreme indices since the beginning of the twentieth century: The HadEX2 dataset. Journal of Geophysical Research-Atmospheres, 118, 2098-2118. https://doi.org/10.1002/jgrd.50150

Dosio, A., and Fischer, E. M. (2018). Will half a degree Make a difference robust projections of indices of mean and extreme climate in Europe under $1.5^{\circ} \mathrm{C}, 2^{\circ} \mathrm{C}$, and $3^{\circ} \mathrm{C}$ global warming. Geophysical Research Letters, 45, 935-944. https://doi.org/10.1002/2017GL076222

Endo, H., Kitoh, A., Mizuta, R., and Ishii, M. (2017). Future Changes in Precipitation Extremes in East Asia and Their Uncertainty Based on Large Ensemble Simulations with a High-Resolution AGCM. SOLA, 13(0), 7-12. doi:10.2151/sola.2017-002

Feng, S., and Fu, Q. (2013). Expansion of global drylands under a warming climate. Atmospheric Chemistry and Physics, 13, 10081-10094. https://doi.org/10.5194/acp-13-10081-2013

Fischer, E. M., Beyerle, U., Schleussner, C. F., King, A. D., and Knutti, R. (2018). Biased estimates of changes in climate extremes from prescribed SST simulations. Geophysical Research Letters, 45(16), 8500-8509. https://doi.org/10.1029/2018GL079176

Fischer, E. M., and Knutti, R. (2015). Anthropogenic contribution to global occurrence of heavy-precipitation and high-temperature extremes. Nature Climate Change, 5, 560-564. https://doi.org/10.1038/nclimate2617

Guan, Y. H., Zheng, F. L., Zhang, X. C., and Wang, B. (2017). Trends and variability of daily precipitation and extremes during 1960-2012 in the Yangtze River Basin, China. International Journal of Climatology, 37, 1282-1298. https://doi.org/10.1002/joc.4776

Huang, J. P., Ji, M. X., Xie, Y. K., Wang, S. S., He, Y. L., and Ran, J. J. (2016b). Global semi-arid climate change over last 60 years. Climate Dynamics, 46, 1131-1150. https://doi.org/ 


\section{$10.1007 / \mathrm{s} 00382-015-2636-8$}

Huang, J. P., Yu, H. P., Dai, A. G., Wei, Y., and Kang, L. T. (2017). Drylands face potential threat under $2^{\circ} \mathrm{C}$ global warming target. Nature Climate Change, 7(6), 417-422. https://doi.org/10.1038/NCLIMATE3275

Huang, J. P., Yu, H. P., Guan, X. D., Wang, G. Y., and Guo, R. X. (2016a). Accelerated dryland expansion under climate change. Nature Climate Change, 6(2), 166-171. https://doi.org/10.1038/NCLIMATE2837

Hurrell, J. W., Holland, M. M., Gent, P. R., Ghan, S., Kay, J. E., Kushner, P. J. et al. (2013). The Community Earth System Model a framework for collaborative research. Bulletin of the American Meteorological Society, 94, 1339-1360. https://doi.org/10.1175/BAMS-D-12-00121.1

Karl, T. R., Nicholls, N., and Ghazi, A. (1999). CLIVAR/GCOS/WMO workshop on indices and indicators for climate extremes: Workshop summary. Climatic Change, 42, 3-7. https://doi.org/ 10.1023/A:1005491526870

Kay, J. E., Deser, C., Phillips, A., Mai, A., Hannay, C., Strand, G. et al. (2015). The community earth system model (CESM) large ensemble project:A community resource for studying climate change in the presence of internal climate variability. Bulletin of the American Meteorological Society, 96, 1333-1349. https://doi.org/10.1175/BAMS-D-13-00255.1

Kharin, V. V., Zwiers, F. W., Zhang, X., and Wehner, M. (2013). Changes in temperature and precipitation extremes in the CMIP5 ensemble. Climatic Change, 119, 345-357. https://doi.org/10.1007/s10584-013-0705-8

King, A. D., Karoly, D. J., and Henley, B. J. (2017). Australian climate extremes at $1.5^{\circ} \mathrm{C}$ and $2^{\circ} \mathrm{C}$ of global warming. Nature Climate Change, 7(6), 412-416. https://doi.org/10.1038/NCLIMATE3296

King, A. D., Knutti, R., Uhe, P., Mitchell, D. M., Lewis, S. C., Arblaster, J. M., and Freychet, N. (2018). On the linearity of local and regional temperature changes from $1.5^{\circ} \mathrm{C}$ to $2^{\circ} \mathrm{C}$ of global warming. Journal of Climate, 31(18), 7495-7514. https://doi.org/10.1175/JCLI-D-17-0649.1

Kusunoki, S. (2017). Future changes in precipitation over East Asia projected by the global atmospheric model MRI-AGCM3.2. Climate Dynamics, 51, 4601-4617. https://doi.org/10.1007/s00382-016-3499-3

Li, D. H., Zhou, T. J., Zou, L. W., Zhang, W. X., and Zhang, L. X. (2018). Extreme high-temperature events over East Asia in $1.5^{\circ} \mathrm{C}$ and $2{ }^{\circ} \mathrm{C}$ warmer futures analysis of NCAR CESM low-warming experiments. Geophysical Research Letters, 45, 1541-1550. https://doi.org/10.1002/2017GL076753

Li, Q., Zhang, R. H., and Wang, Y. (2016). Interannual variation of the wintertime fog-haze days across central and eastern China and its relation with East Asian winter monsoon. International 
Journal of Climatology, 36, 346-354. https://doi.org/10.1002/joc.4350

Lin, L., Wang, Z. L., Xu, Y. Y., and Fu, Q. (2016). Sensitivity of precipitation extremes to radiative forcing of greenhouse gases and aerosols. Geophysical Research Letters, 43(18), 9860-9868. https://doi.org/10.1002/2016GL070869

Lin, L., Wang, Z. L., Xu, Y. Y., Zhang, X. Y., Zhang, H., and Dong, W. J. (2018). Additional intensification of seasonal heat and flooding extreme over China in a $2^{\circ} \mathrm{C}$ warmer world compared to $1.5^{\circ}$ C. Earths Future, 6(7), 968-978. https://doi.org/10.1029/2018EF000862

Middleton, N. J., and Thomas, D. S. G. (1997). World atlas of desertification, 2ndedn. Arnold, a member of the Hodder Headline Group, London.

Mitchell, D., Heaviside, C., Vardoulakis, S., Huntingford, C., Masato, G. Guillod, B. P. et al. (2016). Attributing human mortality during extreme heat waves to anthropogenic climate change. Environmental Research Letters, 11(7), 074006. https://doi.org/10.1088/1748-9326/11/7/074006

Orlowsky, B., and Seneviratne, S. I. (2012). Global changes in extreme events: regional and seasonal dimension. Climatic Change, 110, 669-696. doi: 10.1007/s10584-011-0122-9

Perkins, S. E., and Alexander, L. V. (2013). On the measurement of heat waves. Journal of Climate, 26, 4500-4517. https://doi.org/10.1175/JCLI-D-12-00383.1

Perkins, S. E., Alexander, L. V., and Nairn, J. R. (2012). Increasing frequency, intensity and duration of observed global heatwaves and warm spells. Geophysical Research Letters, 39, L20714. https://doi.org/10.1029/2012GL053361

Peterson, T. C. et al. Report on the Activities of the Working Group on Climate Change Detection and Related Rapporteurs 1998-2001. WMO, Rep. WCDMP-47, WMO-TD 1071, Geneve, Switzerland, 143pp.

Ren, G. Y., and Zhou, Y. Q. (2014). Urbanization effect on trends of extreme temperature indices of national stations over mainland China, 1961-2008. Journal of Climate, 27, 2340-2360. https://doi.org/10.1175/JCLI-D-13-00393.1

Sanderson, B. M., O'Neill, B., and Tebaldi, C. (2016). What would it take to achieve the Paris temperature targets? Geophysical Research Letters, 43, 7133-7142. https://doi.org/10.1002/2016GL069563

Sanderson, B. M., Xu, Y. Y., Tebaldi, C., Wehner, M., O'Neill, B., Jahn, A. et al. (2017). Community climate simulations to assess avoided impacts in $1.5^{\circ} \mathrm{C}$ and $2{ }^{\circ} \mathrm{C}$ futures. Earth System Dynamics, 8, 827-847. https://doi.org/10.5194/esd-8-827-2017

Scheff, J., and Frierson, D. M. W. (2014). Scaling potential evapotranspiration with greenhouse warming. Journal of Climate, 27, 1539-1558. https://doi.org/10.1175/JCLI-D-13-00233.1

Scherrer, S. C., Fischer, E. M., Posselt, R., Liniger, M. A., Croci-Maspoli, M., and Knutti, R. 
(2016). Emerging trends in heavy precipitation and hot temperature extremes in Switzerland. Journal of Geophysical Research-Atmospheres, 121, 2626-2637.

https://doi.org/10.1002/2015JD024634

Schleussner, C. F., Lissner, T. K., Fischer, E. M., Wohland, J., Perrette, M., Golly, A. et al. (2016). Differential climate impacts for policy-relevant limits to global warming: the case of $1.5^{\circ} \mathrm{C}$ and $2{ }^{\circ}$ C. Earth System Dynamics, 7(2), 327-351. https://doi.org/10.5194/esd-7-327-2016

Sillmann, J., Kharin, V. V., Zhang, X., Zwiers, F. W., and Bronaugh, D. (2013a). Climate extremes indices in the CMIP5 multimodel ensemble: Part 1. Model evaluation in the present climate. Journal of Geophysical Research-Atmospheres, 118, 1716-1733. https://doi.org/10.1002/jgrd.50203

Sillmann, J., Kharin,V. V., Zhang, X., Zwiers, F. W., and Bronaugh, D. (2013b). Climate extremes indices in the CMIP5 multimodel ensemble: Part 2. Future climate projections. Journal of Geophysical Research-Atmospheres, 118, 2473-2493. https://doi.org/10.1002/jgrd.50188

Stone, D. A., and Allen, M. R. (2005), The end-to-end attribution problem: From emissions to impacts. Climatic Change, 71, 303-318. https://doi.org/10.1007/s10584-005-6778-2

Wang, Z. L., Lin, L., Zhang, X. Y., Zhang, H., Liu, L. K., and Xu, Y. Y. (2017). Scenario dependence of future changes in climate extremes under $1.5^{\circ} \mathrm{C}$ and $2^{\circ} \mathrm{C}$ global warming. Scientific Reports, 7, 46432. https://doi.org/10.1038/srep46432

Wei, Y., Yu, H. P., Huang, J. P., Zhou, T. J., Zhang, M., and Ren, Y. (2019). Drylands climate response to transient and stabilized $2^{\circ} \mathrm{C}$ and $1.5^{\circ} \mathrm{C}$ global warming targets: Climate Dynamics, 53(3-4), 2375-2389.

Xing, W., Wang, B., and Yim, S. Y. (2016). Peak-summer East Asian rainfall predictability and prediction part I: Southeast Asia. Climate Dynamics, 47, 1-13. https://doi.org/10.1007/s00382-014-2385-0

Yang, L., Villarini, G., Smith, J. A., Tian, F. Q., and Hu, H. P. (2013). Changes in seasonal maximum daily precipitation in China over the period 1961-2006. International Journal of Climatology, 33, 1646-1657. https://doi.org/10.1002/joc.3539

Zhai, P. M., Zhang, X. B., Wan, H., and Pan, X. H. (2005). Trends in total precipitation and frequency of daily precipitation extremes over China. Journal of Climate, 18, 1096-1108. https://doi.org/10.1175/JCLI-3318.1

Zhang, M., Yu, H. P., Huang, J. P., Wei, Y., Liu, X. Y., and Zhang, T. H. (2019). Comparison of extreme temperature response to $0.5^{\circ} \mathrm{C}$ additional warming between dry and humid regions over East-Central Asia. International Journal of Climatology, 39, 3348-3364. https://doi.org/10.1002/joc.6025

Zhang, W. X., Zhou, T. J., Zou, L. W., Zhang, L. X., and Chen, X. L. (2018). Reduced exposure to extreme precipitation from $0.5^{\circ} \mathrm{C}$ less warming in global land monsoon regions. Nature 
Communications, 9, 3153. https://doi.org/10.1038/s41467-018-05633-3

Zhang, W., Zhou, T., Zhang, L., and Zou, L. (2019). Future intensification of the water cycle with an enhanced annual cycle over global land monsoon regions. Journal of Climate, 32, 5437-5452. https://doi.org/10.1175/jcli-d-18-0628.1

Zhao, G. J., Huang, G., Wu, R. G., Tao, W. C., Gong, H. N., Qu, X., and Hu, K. M. (2015). A new upper-level circulation index for the East Asian summer monsoon variability. Journal of Climate, 28(24), 9977-9996. https://doi.org/10.1175/JCLI-D-15-0272.1

Zhou, S. J., Huang, G., and Huang, P. (2018). Changes in the East Asian summer monsoon rainfall under global warming: moisture budget decompositions and the sources of uncertainty. Climate Dynamics, 51(4), 1363-1373. https://doi.org/10.1007/s00382-017-3959-4

Zhou, T. J., and Chen, X. L. (2015). Uncertainty in the $2{ }^{\circ} \mathrm{C}$ warming threshold related to climate sensitivity and climate feedback. Journal of Meteorological Research, 29(6), 884-895. https://doi.org/10.1007/s13351015-5036-4 
Click here to access/download Supplementary Material supplementary materials.docx 


\title{
Greater probability of extreme precipitation under $1.5^{\circ} \mathrm{C}$ and $2^{\circ} \mathrm{C}$
}

\section{warming limits over East-Central Asia}

\author{
Meng Zhang ${ }^{1,2}$, Haipeng Yu ${ }^{1,3}$, Andrew D. King ${ }^{4}$, Yun $\mathrm{Wei}^{2}$, \\ Jianping Huang ${ }^{5}$, Yu Ren ${ }^{2}$
}
${ }^{1}$ Key Laboratory of Land Surface Process and Climate Change in Cold and Arid Regions, Northwest Institute of Eco-Environment and Resources, Chinese Academy of Sciences, Lanzhou, China
${ }^{2}$ Key Laboratory for Semi-Arid Climate Change of the Ministry of Education, College of Atmospheric Sciences, Lanzhou University, Lanzhou, China
${ }^{3}$ Key Laboratory of Arid Climatic Change and Disaster Reduction in Gansu Province, Key Open Laboratory of Arid Climatic Change and Disaster Reduction in CMA, Institute of Arid Meteorology, CMA, Lanzhou, China ${ }^{4}$ ARC Centre of Excellence for Climate Extremes, School of Earth Sciences, University of Melbourne, Melbourne 3010, Australia
${ }^{5}$ Collaborative Innovation Center for Western Ecological Safety, Lanzhou University, Lanzhou, China

Corresponding author: Haipeng Yu (hpyu09@1zu.edu.cn)

Additional author: Meng Zhang (zhangm2012@1zu.edu.cn)

Andrew D. King (andrew.king@unimelb.edu.au)

Yun Wei (weiy16@1zu.edu.cn)

Jianping Huang (hjp@lzu.edu.cn)

Yu Ren (yren15@1zu.edu.cn) 


\section{Abstract}

East-Central Asia is one of the most vulnerable and sensitive regions to climate change, and the variability of extreme precipitation attracts great attention due to the large population and the importance of its economy. Here, three special runs with the Community Earth System Model (CESM) are used to project the changes of $\underline{\text { in }}$ representative extreme precipitation indices (Rx1day, Rx5day, R95p, SDII) over East-Central Asia under the $1.5^{\circ} \mathrm{C}$ and $2^{\circ} \mathrm{C}$ Paris Agreement limits. The results indicate that Rx1day and Rx5day will increase by $28 \%$ and $15 \%$-respectively under, respectively, under the $1.5^{\circ} \mathrm{C}$ warming level relative to the historical period (1971-2000). Most areas over East-Central Asia are projected to experience an accelerated increase in response to a further $0.5^{\circ} \mathrm{C}$ warming. Specifically, humid areas (HAs $)$ are projected to experience more-experience a greater increase in R95p annual days and area fraction, whereas arid and semi arid-semiarid areas (ASA $\underline{s}$ ) may have three times higher risks. The proportion of extreme precipitation in total will increase $\sim 10 \%$ in most $\mathrm{HA} \underline{\mathrm{HAs}}$ in response to the $0.5^{\circ} \mathrm{C}$ additional warming. Holding global warming at $1.5^{\circ} \mathrm{C}$ instead of $2^{\circ} \mathrm{C}$ reduces the occurrence of $\mathrm{R} 95 \mathrm{p}$ annual days by $\sim$ three days/year in humid areas and one day/year in ASA respectivelyASAs. For

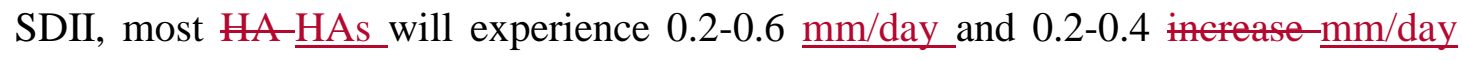
increases in $1.5^{\circ} \mathrm{C}$ or $2^{\circ} \mathrm{C}$ warming limits, especially in Southeast China and the Himalayas. Therefore, limiting global warming to under $1.5^{\circ} \mathrm{C}$ is beneficial to reducing the occurrence and associated impact of precipitation extremes in East-Central Asia.

Keywords: extreme precipitation, $1.5^{\circ} \mathrm{C}$ and $2{ }^{\circ} \mathrm{C}$ warming limits, East-Central Asia, arid and semi-arid-semiarid areas, humid areas 


\section{Introduction}

As a meteorological phenomenon, extreme precipitation is responsible for many catastrophes and often causes disasters such as floods, which have great impacts on economic development, social stability and people's livelihoods (Orlowsky and Seneviratne, 2012; Yang et al., 2013; Scherrer et al., 2016). For instance, prolonged heavy precipitation led to the worst flooding in Pakistan's history in 2010, resulting in nearly 3,000 deaths and affecting 20 million people. In Nara Prefecture of Japan, the 72-hour rainfall record was broken in 2011, and that event resulted in 73 deaths and 20 missing (Coumou and Rahmstorf, 2012). It is crucial that the understanding of

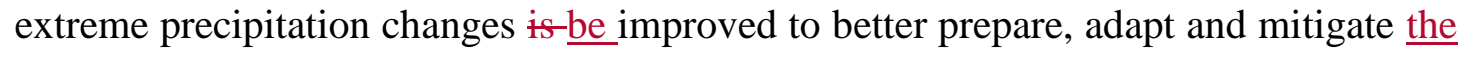
impacts of future events as the climate changes.

Due to the effect of the of land-sea thermal differencedifferences and human activities, East-Central Asia $\left(10^{\circ}-55^{\circ} \mathrm{N}, 60^{\circ}-150^{\circ} \mathrm{E}\right)$ is one of the world's most vulnerable regions of the world-to extreme precipitation and its consequences (Zhai et al., 2005; Ren and Zhou, 2014; Zhao et al., 2015; Lin et al., 2016; Guan et al., 2017; Zhou et al., 2018). Given the impacts of precipitation extremes, they $\underline{\text { such extremes }}$ have become a topic of interest in recent understanding of historic changes and future projections especially prominent (Alexander et al., 2006; Kharin et al., 2013; Sillmann et al., 2013a; Sillmann et al., 2013b). Since the Paris Agreement set a goal for limiting global warming below $2^{\circ} \mathrm{C}$, $\underline{\mathrm{C}}$ and preferentially to $1.5^{\circ} \mathrm{C}, \underline{\mathrm{C} \text { relative to pre-industrial levels }}$, the variation ef $\underline{\mathrm{in}}$ extreme climate conditions under future warming scenarios has also become an area of active research (Zhou and Chen, 2015; Chen and Sun, 2018; Dosio and Fischer, 2018; Li et al., 2018; Wei et al., 2019). Lin et al. (2018) indicated that the average precipitation in China will increase by $11.6 \%\left(1.5^{\circ} \mathrm{C}\right)$ and $13.3 \%\left(2^{\circ} \mathrm{C}\right)$ based on 1976-2005. Chen and Sun (2017) pointed out that human influence will cause half of the occurrence probability increase of severe extremes in China. Zhang et al. (2018) indicated that the $-0.5^{\circ} \mathrm{C}$ further warming would aggravate areal and population exposures to once-in-20-year extreme precipitation events by $25 \%$ in East Asia. 
Kusunoki pointed out that almost all eastern China areas are projected to experience more precipitation during 2079 to 2099. Some other Other studies have also pointed out that the-continued global temperature increase is-increases are projected to induce more extreme precipitation events in the future (Endo et al., 2017; Wang et al., 2017). There are several methods that can be used to form projections for climate extremes in different warmer worlds (e.g.-.., the Coupled Model Intercomparison Project phase 5 (CMIP5) time-sampling and prescribed sea surface temperature (SST) simulations) (Mitchell et al., 2016; Schleussner et al., 2016; King et al., 2017). CMIP5 timesampling may utilize all four representative concentration pathways (RCPs) to generate a large sample of model years, but these are based on transient climates for low-end global warming limits, such as $1.5^{\circ} \mathrm{C}$ and $2^{\circ} \mathrm{C}$. Atmosphere-only model simulations use prescribed SSTs, representing the recent period but with additional warming, to project future climates. However, there is an assumption that the recent period is representative of current climate variability and that coupled processes are not important to the extreme being investigated (Fischer et al., 2018). Here, we utilized three CESM-Community Earth System Model (CESM) experiments to analyze the spatiotemporal difference between the $1.5^{\circ} \mathrm{C}$ and $2^{\circ} \mathrm{C}$ warming limits and the recent historical period (Sanderson et al., 2017; Zhang et al., 2019). To our knowledge, the researches for -research on East-Central Asia extreme precipitation prediction-predictions using CESM $1.5^{\circ} \mathrm{C}$ and $2^{\circ} \mathrm{C}$ low warming runs (LWR) are searcity. is scarce.

Precipitation in East-Central Asia is distributed unevenly owing to the influence of the monsoon and warm moist air from the ocean (Li et al., 2016; Xing et al., 2016). Monsoon areas have abundant precipitation-whereas, while inland areas, where there is a relative lack of water vapor source, have little precipitation but high potential evapotranspiration. This difference in the mean climate state and interannual variability in the monsoon poses a challenge to water supply management (Huang et al., 2016a; Huang et al., 2017). The difference in background climate state and in precipitation extremes between these regions makes it necessary to analyze them separately. Thus, in order to be more precise and objective, we divide East-Central 
109 Asia into two subparts based on the aridity index (AI): HA humid areas (HAs) and

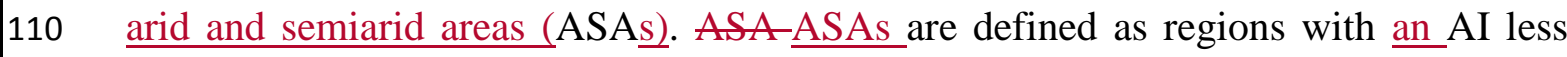
111 than 0.65 (Middleton and Thomas, 1997). We utilized the AI provided by Feng and Fu 112 (2013) and calculated for the historical period as a basis for the dry-wet division. For 113 more details about about the AI, please refer to (Scheff and Frierson, 2014; Huang et 114 al., 2016b).

115 In this paper, we compare and analyze four relevant and widely used extreme 116 precipitation indices (Rx1day, Rx5day, R95p and SDII) (Karl et al., 1999; Peterson et 117 al., 2001) and try to answer the following three questions: (1) Will a remarkable 118 difference appear in East-Central Asia under a $1.5^{\circ} \mathrm{C}$ or $2^{\circ} \mathrm{C}$ global warming future? 119 (2) What is the difference due to a further $0.5^{\circ} \mathrm{C}$ warming? (3) Are there differences in 120 projections for ASA $\underline{\mathrm{ASAs}}$ and HAs? 


\section{Data and Methods}

\subsection{Model data}

We used the fully coupled climate model CESM released by by the National Center for Atmospheric Research (NCAR) for our analysis on of extreme precipitation projections under $1.5^{\circ} \mathrm{C}$ and $2^{\circ} \mathrm{C}$ global warming limits (Hurrell et al., 2013). The CESM LWR comprise of comprises a 10 -member ensemble for $1.5^{\circ} \mathrm{C}$ and $2^{\circ} \mathrm{C}$ scenarios called $1 \mathrm{pt} 5$ and 2pt, respectively (Kay et al., 2015; Sanderson et al., 2016). By setting the radiative forcing of greenhouse gases, the global mean temperature relative to pre-industrial levels would rise monotonically to $1.5^{\circ} \mathrm{C}\left(2^{\circ} \mathrm{C}\right)$ by 2090-2100 under LWR 1pt5 (2pt) scenarios. We also used RCP4.5 and RCP8.5 to provide further comparisencomparisons. The number of runs in the CESM models

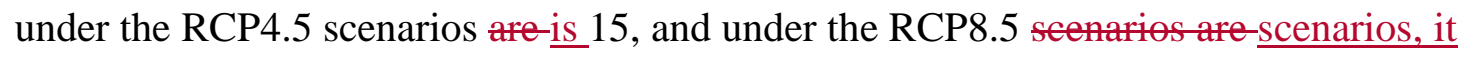
is 30. Under RCPs, wWe define the $1.5^{\circ} \mathrm{C}$ or $\left(2^{\circ} \mathrm{C}\right)$ global warming level as the 4 years-11-year average mean-window based on the centers of chosen years (RCP4.5 and $\mathrm{RCP} 8.5)$ when , the 11 -year mean temperature rise to $1.5^{\circ} \mathrm{C}\left(2^{\circ} \mathrm{C}\right)$ relative to pre-industrial levelswhich are the exact time times to achieve the target temperature $\left(1.5^{\circ} \mathrm{C}\right.$ or $\left.2^{\circ} \mathrm{C}\right)$. For the Low Warming RunsLWR, we directly used 20902100 as the average mean directlymean. Therefore, tThis definition is definition may be more accurate suitable than chose choosing a certain year directly. The CESM LWR scenario represents simulations will be closer tothe -equilibrium climate response while the RCPs than-represent transient climate response scenarios like-scenariossuch as RCPs. The equilibrium climate response scenario means that the average global warming will stabilize at be $-1.5^{\circ} \mathrm{C}$ or $2^{\circ} \mathrm{C}$ by the end of the 21 st century. Moreover, the carbon dioxide equivalence emission is matched with global temperature rises. For tSo Therefore, the increase of increase in the average globat temperature will stabilize at $1.5^{\circ} \mathrm{C}$ or $2^{\circ} \mathrm{C}$ for some years. As for the transient Transient climate responses, such as RCP4.5 and RCP8.5, the global mean temperature would it is only pass pass through $1.5^{\circ} \mathrm{C}$ or $2^{\circ} \mathrm{C}$, and the final increase exceeds these two warming limits. This response usually overestimates - 
overestimate the temperature increase and it causes-cause some related influence. The dynamic and thermodynamic system-systems of climate model simulation are not not in equilibrium. Based on the climate model work principle, the equilibrium response scenario is considered more accurate-acceptable than the transient one. More details about CESM experiments can be found in Sanderson et al. (2017).

\subsection{Extreme precipitation indices}

Four extreme precipitation indices defined by the Expert Team for Climate Change Detection Monitoring and Indices (ETCCDI) were selected for analysis of the changes in extreme precipitation events in warmer futures (Perkins et al., 2012; Donat et al., 2013; Perkins and Alexander, 2013). Further details of the four selected extreme precipitation indices are provided in Table 1.

Table 1: Core set of of four selected four extreme indices recommended by the ETCCDI.

\begin{tabular}{|c|c|c|c|}
\hline Label & Name & Definition & Units \\
\hline RX1day & $\begin{array}{l}\text { Maximum } 1 \text { day } \\
\text { precipitation }\end{array}$ & $\begin{array}{l}\text { Let } \mathrm{PR}_{\mathrm{ij}} \text { be the daily precipitation amount on day } \mathrm{i} \text { in period } \mathrm{j} \text {. } \\
\text { The maximum } 1-1 \text {-day value for period } \mathrm{j} \text { are } \\
R X 1 d a y_{j}=\max \left(P R_{i j}\right) \\
\text { It should be noted that the annual values are average monthly } \\
\text { values. }\end{array}$ & $\mathrm{mm}$ \\
\hline RX5day & $\begin{array}{l}\text { Maximum consecutive } \\
5 \text { days precipitation }\end{array}$ & $\begin{array}{l}\text { Let } P R_{k j} \text { be the precipitation amount for the } 5-5 \text {-day interval } \\
\text { ending } \mathrm{k} \text {, period } \mathrm{j} \text {. Then-Then, maximum 5--day values for } \\
\text { period } \mathrm{j} \text { are } R X 5 \text { day }_{j}=\max \left(P R_{k j}\right) \\
\text { It should be noted that the annual values are average monthly } \\
\text { values. }\end{array}$ & $\mathrm{mm}$ \\
\hline R95p & $\begin{array}{l}\text { Very Annual total } \\
\text { precipitation in very } \\
\text { wet days }\end{array}$ & $\begin{array}{l}\text { Let } \mathrm{PR}_{\mathrm{wj}} \text { be the daily precipitation amount on a wet day } \mathrm{w} \text { in } \\
\text { period } \mathrm{i} \text { and let } \mathrm{PR}_{\mathrm{wn}} 95 \text { be the } 95 \text { th percentile of precipitation } \\
\text { on wet days in the } 1971-2000 \text { period-. If } \mathrm{W} \text { represents the } \\
\text { number of wet days in the period, then } R 95_{p j}=\sum_{w=1}^{W} P R_{w j} \\
\left(P R_{w j}=P R_{w n} 95\right)\end{array}$ & $\mathrm{mm}$ \\
\hline SDII & Simple daily intensity & Let $P_{w w}$ be the daily precipitation amount on wet days, $P R>=$ & $\mathrm{mm} / \underline{\mathrm{da}}$ \\
\hline
\end{tabular}




$$
S D I I_{j}=\left(\sum_{w=1}^{W} P R_{w j}\right) / W
$$

165

166

167

168

169

170

171

172

Rx1day and Rx5day are probably related to specific____ and possibly meteorologically distinct extreme precipitation events. R95p is useful in reflecting the absolute value change ef in total annual extreme precipitation. SDII is used to measure the intensity of precipitation in-on wet days. Fogether Together, these indices are useful in extending our understanding of the changing likelihood of extreme precipitation under $1.5^{\circ} \mathrm{C}$ and $2^{\circ} \mathrm{C}$ warming limits.

\subsection{Probability ratio}

Probability The probability ratio (PR) is a metric to measure the probability of a specific event has having changed. The formula and method eomes-come from the epidemiological field. Since being introduced to the climate change study area, PR is has been used to detect the risk of the events occurring. The PR as a detection and attribution method represents the extent that extent to which external foreing forcing, such as global warming and the overall anthropogenic influence on the climate, affect extreme precipitation events (Fischer and Knutti, 2015). The formula used is as shown in (1).

$$
\mathrm{PR}=\mathrm{P}_{1} / \mathrm{P}_{0}
$$

Here, $\mathrm{P}_{0}$ refers to the extreme precipitation indices in a historical period (note

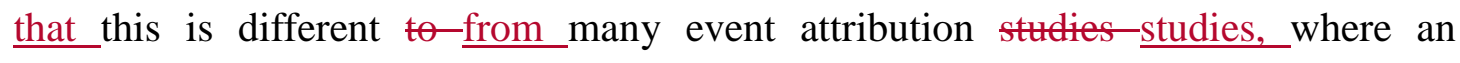
approximation for a pre-industrial climate is represented by $\left.\mathrm{P}_{0}\right)$ and $\mathrm{P}_{1}$ represents the probability of the event under under a $1.5^{\circ} \mathrm{C}$ or $2^{\circ} \mathrm{C}$ warming future. The PR statistic

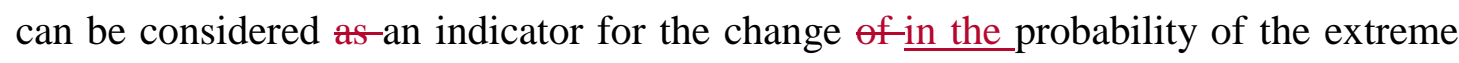
precipitation indices: the reference value is 1.0 , which would mean future likelihoods are the same as now. If PR>1.0, the occurrence (for Rx1day and Rx5day) or intensity (for R95p and SDII) of precipitation extremes will increase-increase, and vice versa (Stone and Allen, 2005). 


\section{Results}

\subsection{Spatiotemporal change in the four indices}

For Rx1day under $1.5^{\circ} \mathrm{C}$ global warming, an obvious dividing line could be found in all four experiments (Figure 1-4). It is worth mentioning that this boundary

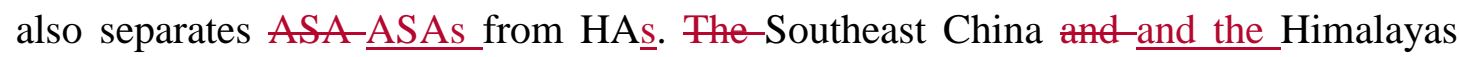
witness a rise of over $2 \mathrm{~mm} 2 \mathrm{~mm}$, based on the CESM LWR simulations, while the rest $\theta \mathrm{HA}$ of the HAs experience a projected increase of $1-2 \mathrm{~mm}-2 \mathrm{~mm}$ in a $1.5^{\circ} \mathrm{C}$ world (Figure 1(a)). The spatial pattern-patterns of RCP4.5 and RCP8.5 are similar to that in LWR. Nevertheless, the absolute increase in Southeast China is lower in the RCPs than in the LWR simulations (Figure 1(c)(e)). There is consistency between Rx1day and Rx5day projections in their spatial pattern. There is a projected increase in Rx5day of over $6 \mathrm{~mm}-6 \mathrm{~mm}$ in Southeast China and the Himalayas according to LWR, three times as much as for Rx1day (Figure 2(a)). The R95p index is projected to increase by over $200 \mathrm{~mm}-200 \mathrm{~mm}$ under $1.5^{\circ} \mathrm{C}$ global warming, such that a larger

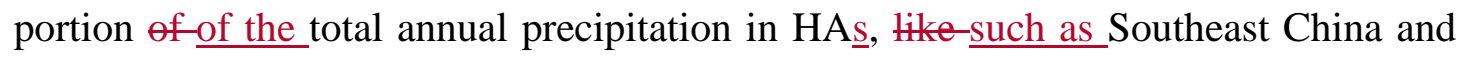
the Himalayas, is due to extreme rainfall (Figure 3(a)). Likewise, RCP4.5 and RCP8.5 in Rx5day and R95p increase less compared with-with the LWR simulations (Figure 2(c)(e) and Figure 3(c)(e)). SDII represents the simple daily intensity of precipitation in-on wet days. If SDII increases in the future, the risk for extreme precipitation will

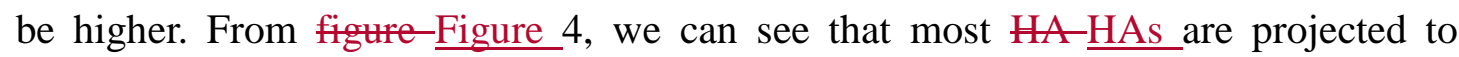
experience a $0.5 \mathrm{~mm} /$ day increase under $1.5^{\circ} \mathrm{C}$ relative to the historical period, whereas SDII in North India will decrease by about approximately $0.5 \mathrm{~mm} /$ day (Figure 4(a)(c)(e))-.

For a further $0.5^{\circ} \mathrm{C}$ warming in Rx1day, some regions (Southeast China and the Himalayas) still experience a modest increase of $0.51 \mathrm{~mm}$-approximately $0.5-1$ $\underline{m m}$ (Figure 1(b)). AlseAdditionally, the difference in spatial pattern between the LWR and the other two experiments narrows (Figure 1(d)(f)). Some regions-regions, such as North China, North India and Pakistan, near the dry-wet transition zone, are simulated to experience a projected minor decrease in Rx1day. In these regions, 
221 increases in temperature and extreme precipitation are not pesitive-positively related.

222 That This phenomenon might be induced by hydrologic cycle issues in the CESM.

223 North India and Pakistan are located in the subtropical ASA $\underline{A S A s}$, which belongs to 224 the sink branch of of the Hadley circulation. An additional $0.5^{\circ} \mathrm{C}$ warming from $1.5^{\circ} \mathrm{C}$ to $2{ }^{\circ} \mathrm{C}$ is likely to cause more moisture divergence and then moisture content reduction (Zhang et al., 2019). Thes-Thus, North India and Pakistan are protected projected to see decrease-decreasing trends in some extreme precipitation indices. The

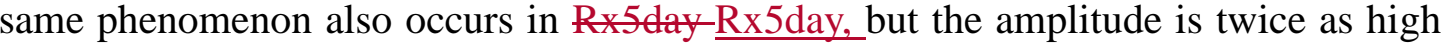
as that for Rx1day (Figure 2(b)(d)(f)). Figure 3(b)(d)(f) illustrates that a further $0.5^{\circ} \mathrm{C}$ warming is associated with an almost $100 \mathrm{~mm}-100 \mathrm{~mm}$ increase in R95p in most of HA-HAs, illustrating a substantial benefit to-of keeping global warming to the more ambitious $1.5^{\circ} \mathrm{C}$ Paris limit. Compared with $200 \mathrm{~mm}$ the $200 \mathrm{~mm}$ rise under the $1.5^{\circ} \mathrm{C}$

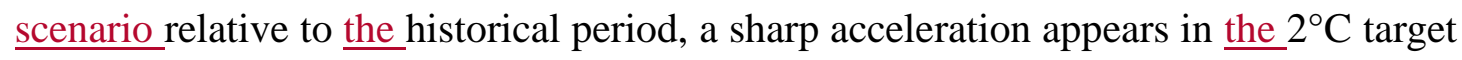
relative to the $1.5^{\circ} \mathrm{C}$ target. This increase-The increasing or decrease-decreasing tendency of SDI-SDII is still maintains-maintained in the mentioned areas (Figure $4(b)(d)(f))$.

However, the -The spatiotemporal change in percentage is different from that in absolute value mentioned before (Figures S1-S4). The change-change in the absolute value of extreme precipitation absolute value -in ASA are-ASAs is relatively small

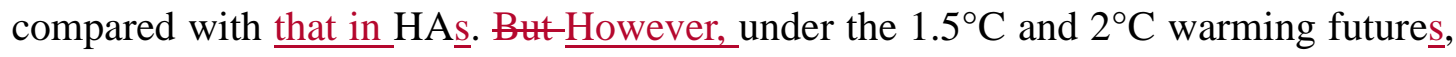
there will be a sharp increase of -increase in the extreme precipitation percentage in

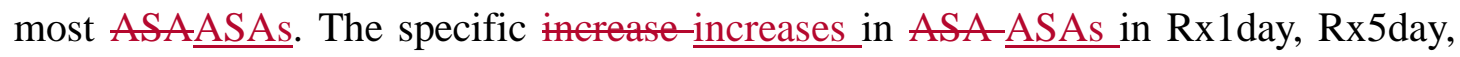
R95p and SDII under $1.5^{\circ} \mathrm{C}$ relative to the historical period are $20-40 \%, 10-30 \%$, $100-200 \%$ and $5-15 \%$, respectively. The additional $0.5^{\circ} \mathrm{C}$ warming provides a further $5-10 \%$ increase in both Rx1day and Rx5day. For R95p, the average increase number is $30-50 \%$. SDII in most ASA ASAs is projected to experience experience a $2-4 \%$ increase, though the although North India and Pakistan will witness a slight decrease.

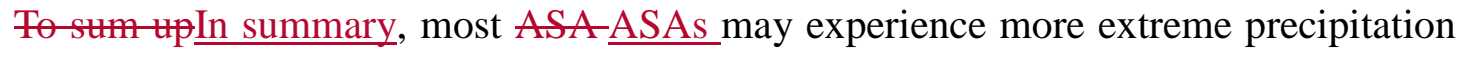
events in the warming future. 


\subsection{Probability ratio change in Rx1day and Rx5day}

The absolute value changes in extreme precipitation under the $1.5^{\circ} \mathrm{C}$ and $2^{\circ} \mathrm{C}$ warming limits show how rainfall extremes are projected to alter in the future, but PR values provide likelihood changes in extremes which that help inform decision-making. Figure 5 shows the statistical distribution of PR values by gridbox in Rx1day and $\mathrm{Rx} 5$ day under the $1.5^{\circ} \mathrm{C}$ and $2^{\circ} \mathrm{C}$ global warming limits relative to the historical period. According to Figure 5(a)-(b), only 5\% of all grid points see a decrease in Rx1day, and the rest of the area is projected to experience increases in this index, especially for the changes higher than the 90th percentile, which rise at a higher rate. For Rx5day, the proportion of all grid points which that experience a PR below one increases from 5\% to $10 \%$. This is unsurprising given that Rx5day is a less extreme rainfall index than Rx1day and will tend-tends to exhibit behavior more similar to the mean. As ean be seen in the figure-shown in Figure 5, there is almost no distinction between-between the $1.5^{\circ} \mathrm{C}$ and $2^{\circ} \mathrm{C}$ representative lines when considering the same experiment. However, obvious differences appear between the three experiments (LWR, RCP4.5, RCP8.5). The CESM LWR simulation rise-rises at the highest rate, then-followed by RCP4.5, and RCP8.5 is presents the lowest rate. The increase at high percentiles -in the indices at high percentiles is higher in the LWR simulations than under the RCPs. This indicates that the influence might be different between transient and quasi-equilibrium simulations. ASA is-ASAs are projected to experience greater relative increases in the upper tail for these indices than HAs. This suggests that ASA ASAs may need to prepare for greater risks from extreme precipitation events under global warming.

For $1.5^{\circ} \mathrm{C}$ relative to the historical period, greater PR values are simulated in East-Central Asia (with PR in most regions of 1.0-1.5) (Figure 6(a)(c)(e)). There is not a-no monotonic increase of $\underline{\text { in } \mathrm{Rx}} \mathrm{R} 1 \mathrm{day}$ under a further $0.5^{\circ} \mathrm{C}$ warming. Central Asia and North India, which are projected to experience substantial increases in precipitation extremes under warming to $1.5^{\circ} \mathrm{C}$, are projected to experience slight decreases between $1.5^{\circ} \mathrm{C}$ and $2^{\circ} \mathrm{C}$ global warming. This again illustrates that warming and precipitation increases are not simply positive correlationpositively correlated. 
However, most regions still show positive correlations between temperature and extreme precipitation changes (Figure $6(\mathrm{~b})(\mathrm{d})(\mathrm{f})$ ). The spatial pattern of Rx5day is

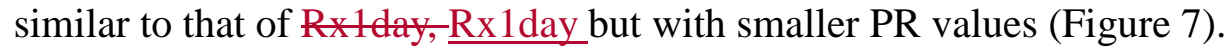

\subsection{Further changes in R95p}

In general, the higher the extreme precipitation propertion isproportion, the greater the probability risks that are projected. . Figure 8 provides the changes of $\underline{-i n}$ $\mathrm{R} 95 \mathrm{p}$ as a percentage of total precipitation-precipitation, and we see that the increases in magnitude exceed $10 \%$ in HA HAs (Figure 8(a)). Under RCP4.5 and RCP 8.5, Southeast China and the Himalayas also experience increases in-in the proportion of extreme precipitation-precipitation, but these are lower than for those projected by the LWR. Other HA HAs have less obvious variation in R95p changes under the RCPs compared with the results of the LWR (Figure 8(c)(e)). Likewise, there is little change in ASA ASAs based on the three experiments. Increasing warming by $0.5^{\circ} \mathrm{C}$ seems like -appears to be a double-edged sword which that would cause some regions (Southeast China and the Himalayas) to experience increased extreme precipitation and other regions (North China and North India) to experience spatially inhomogeneous changes and perhaps even decreases (Figure 8(b)(d)(f)).

We use the R95p annual days change to describe the variation intensity the and R95p area fraction change for the variation range. R95p annual days means the count of total annual days which that meet the definition of R95p-. The R95p area fraction indicates the variation of the R95p percentage shift to positive or negative. Under the background of extreme precipitation increasing, R95p annual days in HA- $\underline{H A s}$ increase by 10.8 days, 3.8 days, and 1.5 days in the $1.5^{\circ} \mathrm{C}$ limits and increase by 13.1 days, 8.4 days, and 4.2 days in the $2^{\circ} \mathrm{C}$ limits according to LWR, RCP4.5 and RCP8.5, respectively. Coincident with spatial pattern changes, the annual days-day variation in ASA ASAs is not obvious (Table S1). From the perspective of the R95p area fraction, $\mathrm{R} 95 \mathrm{p}$ in most of HA $\underline{\mathrm{HAs}}$ is projected to see increases both under the $1.5^{\circ} \mathrm{C}$ and the $2{ }^{\circ} \mathrm{C}$ warming limits. In contrast, only half of ASA is $\underline{A S A s}$ are expected to witness more R95p, and the proportion of R95p in ASA ASAs increases only slightly under 
$3110.5^{\circ} \mathrm{C}$ further warming (Table S2). 


\section{The mechanisms and uncertainty of the results}

From the CESM model-model's extreme precipitation prediction results, we can conclude that along with the mean temperature increase, the extreme precipitation response is uneven in different areas. In the $1.5^{\circ} \mathrm{C}$ and $2^{\circ} \mathrm{C}$ warming future, ASA

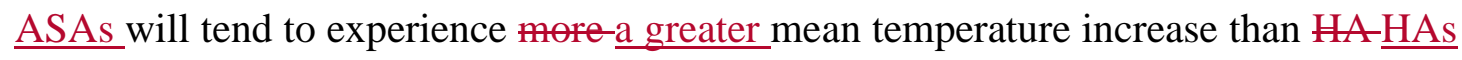

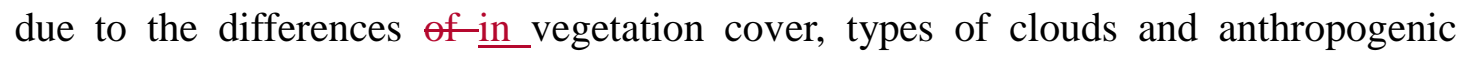
aerosols (Huang et al., 2017). The lower vegetation cover in ASA ASAs leads to lower transpiration rates, resulting in higher surface air temperatures. The thick low clouds in HA $\underline{H A s}$ can effectively reflect shortwave sunlight effectively sunlight, and their low cloud tops result in limited longwave warming effecteffects. On the eontraryIn contrast, most cirrus clouds in ASA ASAs reflect less sunlight to the top atmosphere but absorb more atmospheric counter radiation, leading to the $\underline{a}$ sharp regional temperature increase. Moreover, anthropogenic aerosols, which effect are eooling likely to cool down the surface air temperaturessurface, are less-less abundant in ASA than ASAs than in HAs. Thus, due to the intensifying warming effect, ASA the ASAs will bear higher extreme precipitation events risks-event risks, and the extreme precipitation percentage variation changes in most ASA ASAs are projected to be more higher than those in the HAs. For the hydrologic cycle, HA $\underline{H A s}$ are likely to witness more increases in moisture convergence and then more total precipitation, whereas - while the moisture divergence in ASA ASAs is anomalous (Zhang et al., 2019). More base precipitation and moisture convergence in the warmer world drive HA $\underline{\mathrm{HAs}}$ to experience more total extreme precipitation increaseincreases.

The CESM is released by NCAR, which and consists of several component models and a coupler. Each module is independent, and they modules are connected by by a coupler (Kay et al., 2015). Although that design may reduce model errors as much as possible, it still has some internal errors that are hard to eliminate because of the simulation deviation of the model to-from the actual atmospheric motion state and errors in coupling. Moreover, some physical processes, parameterized schemes and dynamic framework are needed to-frameworks must be constantly improved. The 
341 CESM LWR begin begins from a slightly different initial atmospheric state (created 342 by randomly perturbing temperatures at the level of round-off error). But-However, 343 there are still some differences among those runs considering extreme precipitation 344 indices. RCP4.5 and RCP8.5 are transient scenarios,-, and the response to $1.5^{\circ} \mathrm{C}$ or $3452{ }^{\circ} \mathrm{C}$ warming limits is not in equilibrium. It This will result in some everestimate in 346 overestimation of the temperature increase and eatusing cause some related influence 347 influence, as mentioned in the model data. Despite the these problems, - , the CESM 348 three special runs used in our paper reveal that the extreme precipitation will increase 349 no matter in regardless of intensity or occurrence under the background of global 350 warming in the future. It This is in line with most other climate models and our 351 knowledge. To better understand the reason for that these uneven changes and its 352 background their underlying physical mechanisms, more specific global and regional 353 climate models are needed-need to be tested in further studies. 


\section{Summary and Conclusions}

We utilized four climate prediction experiments from CESM to investigate changes in extreme precipitation under the $1.5^{\circ} \mathrm{C}$ and $2{ }^{\circ} \mathrm{C}$ global warming limits over East-Central Asia. In- Under the $1.5^{\circ} \mathrm{C}$ warming limits, extreme precipitation is projected to increase in almost all regions, especially in the-Southeast China and-and

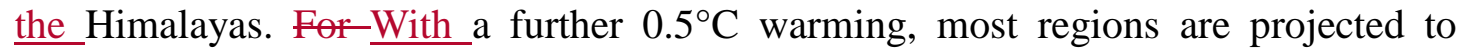
experience a further increase in extreme precipitation-precipitation, although it is not a linear increase. Overall, there will be more extreme precipitation over East-Central Asia under global warming.

According to the LWR, Southeast China and the Himalayas will witness over $2 \mathrm{~mm}$ and $6 \mathrm{~mm}$ increase $2 \mathrm{~mm}$ and $6 \mathrm{~mm}$ increases in Rx1day and Rx5day in the $1.5^{\circ} \mathrm{C}$ warming future, respectively. However, RCP4.5 and RCP8.5 suggest only a slight increase (perhaps due to a difference between transient and quasi-equilibrium responses). For the $2^{\circ} \mathrm{C}$ limit relative to $1.5^{\circ} \mathrm{C}$, the response of $\mathrm{HA}-\underline{\mathrm{HAs}}$ to

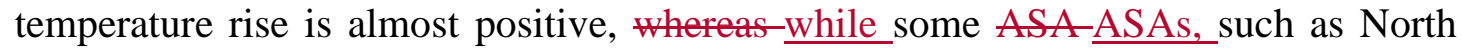
India, North China-, and Northeast Mongolia-Mongolia, indicate a moderate decrease.

The PR of Rx1day and Rx5day will grow exponentially with the-increasing of percentile thresholds, indicating that the most intense extreme precipitation events will occur more frequently in the warming future. It is worth mentioning that the slope of PR in ASA ASAs will be greater than that in HAs, which means a higher relative increase in risk. Considering that $\mathrm{ASA}$ is $\underline{\mathrm{ASAs}}$ are less resistant and more vulnerable to storms and floods, extreme precipitation events may cause more disasters here unless adequate adaptation plans are put in place.

There is projected to be over $200 \mathrm{~mm}$ an over $200-\mathrm{mm}$ increase in the amplitude of $\mathrm{R} 95 \mathrm{p}$ in a $1.5^{\circ} \mathrm{C}$ future and a further $100 \mathrm{~mm}-100-\mathrm{mm}$ increase in $2^{\circ} \mathrm{C}$ relative to $1.5^{\circ} \mathrm{C}$ in Southeast China and and the Himalayas. The proportion of R95p in total precipitation will also have a modest increase of about approximately $10 \%-20 \%$ in the regions previously mentioned. Nevertheless, ASA is $\mathrm{ASAs}$ are expected to 
383 experience spatially inhomogeneous ehange-changes in the contribution of extreme 384 precipitation to total precipitation. That This difference is also reflected in the 385 changes of $-\underline{\text { n R }}$ 95p annual days and the percentage of R95p area. Approximately 5 386 days a 5-day increase under $1.5^{\circ} \mathrm{C}$ and 8 days an 8-day increase under $2^{\circ} \mathrm{C}$ are 387 expected to appear in HAs. Half of ASA the ASAs locations are expected to 388 experience an increase and half a decrease in R95p annual days. Likewise, only HA $389 \quad$ HAs are expected to experience large increases in $\underline{i n}$ the R95p area fraction.

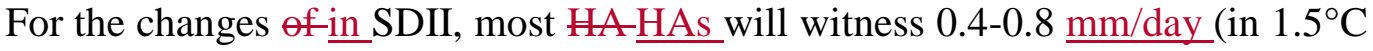
391 relative to the historical period) and $0.2-0.4 \mathrm{~mm} /$ day (in $2^{\circ} \mathrm{C}$ relative to $1.5^{\circ} \mathrm{C}$ ) 392 increaseincreases. North India and Pakistan are projected to experience

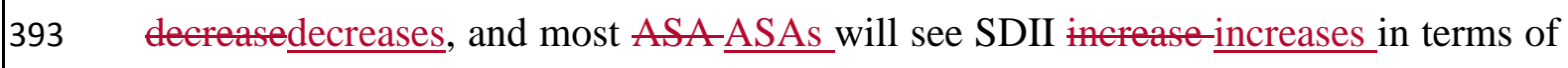
$394 \quad$ values and percentiles. 


\section{Acknowledgements}

396 This work was jointly supported by the National Natural Science Foundation of 397 China $(41705077,41630426)$ and, the National Key Research and Development 398 Program of China (2017YFC1502305), -and China Postdoctoral Science Foundation 399 (2017M613250). ADK was funded by the Australian Research Council 400 (DE180100638). The authors acknowledge the NCAR for releasing the CESM 401 low-warming experiment products and the data were acquired from 402 http://www.cesm.ucar.edu/experiments/1.5-2.0-targets.htmlhtml $403 \quad$ The authors thank the two anonymous reviewers for their valuable suggestions. 


\section{References}

Alexander, L. V., Zhang, X., Peterson, T. C., Caesar, J., Gleason, B., Tank, A. M. G. K., et al. (2006). Global observed changes in daily climate extremes of temperature and precipitation. Journal of Geophysical Research-Atmospheres, 111, D05109. https://doi.org/10.1029/2005JD006290

Chen, H. P., and Sun, J. Q. (2017). Contribution of human influence to increased daily precipitation extremes over China. Geophysical Research Letters, 44(5), 2436-2444. https://doi.org/ 10.1002/2016GL072439

Chen, H. P., and Sun, J. Q. (2018). Projected changes in climate extremes in China in a $1.5^{\circ} \mathrm{C}$ warmer world. International Journal of Climatology, 38(9), 3607-3617. doi: 10.1002/joc.5521

Coumou, D., and Rahmstorf, S. (2012). A decade of weather extremes. Nature Climate Change, 2 , 491-496. https://doi.org/10.1038/NCLIMATE1452

Donat, M. G., Alexander, L. V., Yang, H., Durre, I., Vose, R., Dunn, R. J. H., et al. (2013). Updated analyses of temperature and precipitation extreme indices since the beginning of the twentieth century: The HadEX2 dataset. Journal of Geophysical Research-Atmospheres, 118, 2098-2118. https://doi.org/10.1002/jgrd.50150

Dosio, A., and Fischer, E. M. (2018). Will half a degree Make a difference robust projections of indices of mean and extreme climate in Europe under $1.5^{\circ} \mathrm{C}, 2^{\circ} \mathrm{C}$, and $3^{\circ} \mathrm{C}$ global warming. Geophysical Research Letters, 45, 935-944. https://doi.org/10.1002/2017GL076222

Endo, H., Kitoh, A., Mizuta, R., and Ishii, M. (2017). Future Changes in Precipitation Extremes in East Asia and Their Uncertainty Based on Large Ensemble Simulations with a High-Resolution AGCM. SOLA, 13(0), 7-12. doi:10.2151/sola.2017-002

Feng, S., and Fu, Q. (2013). Expansion of global drylands under a warming climate. Atmospheric Chemistry and Physics, 13, 10081-10094. https://doi.org/10.5194/acp-13-10081-2013

Fischer, E. M., Beyerle, U., Schleussner, C. F., King, A. D., and Knutti, R. (2018). Biased estimates of changes in climate extremes from prescribed SST simulations. Geophysical Research Letters, 45(16), 8500-8509. https://doi.org/10.1029/2018GL079176

Fischer, E. M., and Knutti, R. (2015). Anthropogenic contribution to global occurrence of heavy-precipitation and high-temperature extremes. Nature Climate Change, 5, 560-564. https://doi.org/10.1038/nclimate2617

Guan, Y. H., Zheng, F. L., Zhang, X. C., and Wang, B. (2017). Trends and variability of daily precipitation and extremes during 1960-2012 in the Yangtze River Basin, China. International Journal of Climatology, 37, 1282-1298. https://doi.org/10.1002/joc.4776

Huang, J. P., Ji, M. X., Xie, Y. K., Wang, S. S., He, Y. L., and Ran, J. J. (2016b). Global semi-arid climate change over last 60 years. Climate Dynamics, 46, 1131-1150. https://doi.org/ 10.1007/s00382-015-2636-8

Huang, J. P., Yu, H. P., Dai, A. G., Wei, Y., and Kang, L. T. (2017). Drylands face potential threat under $2^{\circ} \mathrm{C}$ global warming target. Nature Climate Change, 7(6), 417-+ $\underline{422}$. https://doi.org/10.1038/NCLIMATE3275

Huang, J. P., Yu, H. P., Guan, X. D., Wang, G. Y., and Guo, R. X. (2016a). Accelerated dryland expansion under climate change. Nature Climate Change, 6(2), 166-+171. https://doi.org/10.1038/NCLIMATE2837

Hurrell, J. W., Holland, M. M., Gent, P. R., Ghan, S., Kay, J. E., Kushner, P. J. et al. (2013). The 
Community Earth System Model a framework for collaborative research. Bulletin of the American Meteorological Society, 94, 1339-1360. https://doi.org/10.1175/BAMS-D-12-00121.1

Karl, T. R., Nicholls, N., and Ghazi, A. (1999). CLIVAR/GCOS/WMO workshop on indices and indicators for climate extremes: Workshop summary. Climatic Change, 42, 3-7. https://doi.org/ 10.1023/A:1005491526870

Kay, J. E., Deser, C., Phillips, A., Mai, A., Hannay, C., Strand, G. et al. (2015). The community earth system model (CESM) large ensemble project:A community resource for studying climate change in the presence of internal climate variability. Bulletin of the American Meteorological Society, 96, 1333-1349. https://doi.org/10.1175/BAMS-D-13-00255.1

Kharin, V. V., Zwiers, F. W., Zhang, X., and Wehner, M. (2013). Changes in temperature and precipitation extremes in the CMIP5 ensemble. Climatic Change, 119, 345-357. https://doi.org/10.1007/s10584-013-0705-8

King, A. D., Karoly, D. J., and Henley, B. J. (2017). Australian climate extremes at $1.5^{\circ} \mathrm{C}$ and $2^{\circ} \mathrm{C}$ of global warming. Nature Climate Change, 7(6), 412-+416. https://doi.org/10.1038/NCLIMATE3296

King, A. D., Knutti, R., Uhe, P., Mitchell, D. M., Lewis, S. C., Arblaster, J. M., and Freychet, N. (2018). On the linearity of local and regional temperature changes from $1.5^{\circ} \mathrm{C}$ to $2^{\circ} \mathrm{C}$ of global warming. Journal of Climate, 31(18), 7495-7514. https://doi.org/10.1175/JCLI-D-17-0649.1

Kusunoki, S. (2017). Future changes in precipitation over East Asia projected by the global atmospheric model MRI-AGCM3.2. Climate Dynamics, 51, 4601-4617. https://doi.org/10.1007/s00382-016-3499-3

Li, D. H., Zhou, T. J., Zou, L. W., Zhang, W. X., and Zhang, L. X. (2018). Extreme high-temperature events over East Asia in $1.5^{\circ} \mathrm{C}$ and $2^{\circ} \mathrm{C}$ warmer futures analysis of NCAR CESM low-warming experiments. Geophysical Research Letters, 45, 1541-1550. https://doi.org/10.1002/2017GL076753

Li, Q., Zhang, R. H., and Wang, Y. (2016). Interannual variation of the wintertime fog-haze days across central and eastern China and its relation with East Asian winter monsoon. International Journal of Climatology, 36, 346-354. https://doi.org/10.1002/joc.4350

Lin, L., Wang, Z. L., Xu, Y. Y., and Fu, Q. (2016). Sensitivity of precipitation extremes to radiative forcing of greenhouse gases and aerosols. Geophysical Research Letters, 43(18), 9860-9868. https://doi.org/10.1002/2016GL070869

Lin, L., Wang, Z. L., Xu, Y. Y., Zhang, X. Y., Zhang, H., and Dong, W. J. (2018). Additional intensification of seasonal heat and flooding extreme over China in a $2^{\circ} \mathrm{C}$ warmer world compared to $1.5^{\circ} \mathrm{C}$. Earths Future, 6(7), 968-978. https://doi.org/10.1029/2018EF000862

Middleton, N. J., and Thomas, D. S. G. (1997). World atlas of desertification, 2ndedn. Arnold, a member of the Hodder Headline Group, London.

Mitchell, D., Heaviside, C., Vardoulakis, S., Huntingford, C., Masato, G. Guillod, B. P. et al. (2016). Attributing human mortality during extreme heat waves to anthropogenic climate change. Environmental Research Letters, 11(7), 074006. https://doi.org/10.1088/1748-9326/11/7/074006

Orlowsky, B., and Seneviratne, S. I. (2012). Global changes in extreme events: regional and seasonal dimension. Climatic Change, 110, 669-696. doi: 10.1007/s10584-011-0122-9

Perkins, S. E., and Alexander, L. V. (2013). On the measurement of heat waves. Journal of 
Climate, 26, 4500-4517. https://doi.org/10.1175/JCLI-D-12-00383.1

Perkins, S. E., Alexander, L. V., and Nairn, J. R. (2012). Increasing frequency, intensity and duration of observed global heatwaves and warm spells. Geophysical Research Letters, 39, L20714. https://doi.org/10.1029/2012GL053361

Peterson, T. C. et al. Report on the Activities of the Working Group on Climate Change Detection and Related Rapporteurs 1998-2001. WMO, Rep. WCDMP-47, WMO-TD 1071, Geneve, Switzerland, 143pp.

Ren, G. Y., and Zhou, Y. Q. (2014). Urbanization effect on trends of extreme temperature indices of national stations over mainland China, 1961-2008. Journal of Climate, 27, 2340-2360. https://doi.org/10.1175/JCLI-D-13-00393.1

Sanderson, B. M., O'Neill, B., and Tebaldi, C. (2016). What would it take to achieve the Paris temperature targets? Geophysical Research Letters, 43, 7133-7142. https://doi.org/10.1002/2016GL069563

Sanderson, B. M., Xu, Y. Y., Tebaldi, C., Wehner, M., O'Neill, B., Jahn, A. et al. (2017). Community climate simulations to assess avoided impacts in $1.5^{\circ} \mathrm{C}$ and $2^{\circ} \mathrm{C}$ futures. Earth System Dynamics, 8, 827-847. https://doi.org/10.5194/esd-8-827-2017

Scheff, J., and Frierson, D. M. W. (2014). Scaling potential evapotranspiration with greenhouse warming. Journal of Climate, 27, 1539-1558. https://doi.org/10.1175/JCLI-D-13-00233.1

Scherrer, S. C., Fischer, E. M., Posselt, R., Liniger, M. A., Croci-Maspoli, M., and Knutti, R. (2016). Emerging trends in heavy precipitation and hot temperature extremes in Switzerland. Journal of Geophysical Research-Atmospheres, 121, 2626-2637. https://doi.org/10.1002/2015JD024634

Schleussner, C. F., Lissner, T. K., Fischer, E. M., Wohland, J., Perrette, M., Golly, A. et al. (2016). Differential climate impacts for policy-relevant limits to global warming: the case of $1.5^{\circ} \mathrm{C}$ and $2^{\circ}$ C. Earth System Dynamics, 7(2), 327-351. https://doi.org/10.5194/esd-7-327-2016

Sillmann, J., Kharin, V. V., Zhang, X., Zwiers, F. W., and Bronaugh, D. (2013a). Climate extremes indices in the CMIP5 multimodel ensemble: Part 1. Model evaluation in the present climate. Journal of Geophysical Research-Atmospheres, 118, 1716-1733. https://doi.org/10.1002/jgrd.50203

Sillmann, J., Kharin,V. V., Zhang, X., Zwiers, F. W., and Bronaugh, D. (2013b). Climate extremes indices in the CMIP5 multimodel ensemble: Part 2. Future climate projections. Journal of Geophysical Research-Atmospheres, 118, 2473-2493. https://doi.org/10.1002/jgrd.50188

Stone, D. A., and Allen, M. R. (2005), The end-to-end attribution problem: From emissions to impacts. Climatic Change, 71, 303-318. https://doi.org/10.1007/s10584-005-6778-2

Wang, Z. L., Lin, L., Zhang, X. Y., Zhang, H., Liu, L. K., and Xu, Y. Y. (2017). Scenario dependence of future changes in climate extremes under $1.5^{\circ} \mathrm{C}$ and $2^{\circ} \mathrm{C}$ global warming. Scientific Reports, 7, 46432. https://doi.org/10.1038/srep46432

Wei, Y., Yu, H. P., Huang, J. P., Zhou, T. J., Zhang, M., and Ren, Y. (2019). Drylands climate response to transient and stabilized $2^{\circ} \mathrm{C}$ and $1.5^{\circ} \mathrm{C}$ global warming targets: Climate Dynamics, 53(3-4), 2375-2389.

Xing, W., Wang, B., and Yim, S. Y. (2016). Peak-summer East Asian rainfall predictability and prediction part I: Southeast Asia. Climate Dynamics, 47, 1-13. https://doi.org/10.1007/s00382-014-2385-0

Yang, L., Villarini, G., Smith, J. A., Tian, F. Q., and Hu, H. P. (2013). Changes in seasonal 
maximum daily precipitation in China over the period 1961-2006. International Journal of Climatology, 33, 1646-1657. https://doi.org/10.1002/joc.3539

Zhai, P. M., Zhang, X. B., Wan, H., and Pan, X. H. (2005). Trends in total precipitation and frequency of daily precipitation extremes over China. Journal of Climate, 18, 1096-1108. https://doi.org/10.1175/JCLI-3318.1

Zhang, M., Yu, H. P., Huang, J. P., Wei, Y., Liu, X. Y., and Zhang, T. H. (2019). Comparison of extreme temperature response to $0.5^{\circ} \mathrm{C}$ additional warming between dry and humid regions over East-Central Asia. International Journal of Climatology, 39, 3348-3364. https://doi.org/10.1002/joc.6025

Zhang, W. X., Zhou, T. J., Zou, L. W., Zhang, L. X., and Chen, X. L. (2018). Reduced exposure to extreme precipitation from $0.5^{\circ} \mathrm{C}$ less warming in global land monsoon regions. Nature Communications, 9, 3153. https://doi.org/10.1038/s41467-018-05633-3

Zhang, W., Zhou, T., Zhang, L., and Zou, L. (2019). Future intensification of the water cycle with an enhanced annual cycle over global land monsoon regions. Journal of Climate, 32, 5437-5452. https://doi.org/10.1175/jcli-d-18-0628.1 upper-level circulation index for the East Asian summer monsoon variability. Journal of Climate, 28(24), 9977-9996. https://doi.org/10.1175/JCLI-D-15-0272.1

Zhou, S. J., Huang, G., and Huang, P. (2018). Changes in the East Asian summer monsoon rainfall under global warming: moisture budget decompositions and the sources of uncertainty. Climate Dynamics, 51(4), 1363-1373. https://doi.org/10.1007/s00382-017-3959-4 sensitivity and climate feedback. Journal of Meteorological Research, 29(6), 884-895. https://doi.org/10.1007/s13351015-5036-4 


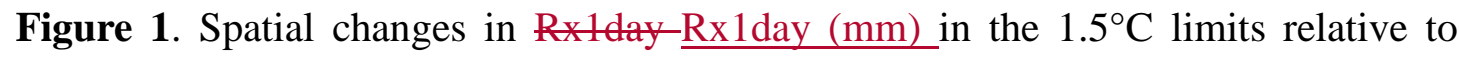
(minus, the same below) the historical period for (a) 1pt5, (c) RCP4.5, (e) RCP8.5. All the same but for $2^{\circ} \mathrm{C}$ relative to $1.5^{\circ} \mathrm{C}$ in (b) $2 \mathrm{pt}$, (d) $\mathrm{RCP} 4.5$, (f) $\mathrm{RCP} 8.5$. The black dotted parts represent ASA $\underline{s}$. The red dotted parts represent the changes are-passing a 95\% significance test.

Figure 2. The same as figure-Figure 1, but for Rx5day (mm).

Figure 3. The same as figure-Figure 1, but for R95p (mm).

Figure 4. The same as figure-Figure 1, but for SDII (mm/day).

Figure 5. (a) PR values in Rx1day in ASA ASAs under $2^{\circ} \mathrm{C}$ and $1.5^{\circ} \mathrm{C}$ limits relative to the historical period. The $* \underline{x}$-axis represents the percentile thresholds based on-on the historical period. The method is as follows: First, we calculate the Rx1day in-in the historical period (average of 30 years) and under the $1.5^{\circ} \mathrm{C}$ warming condition in each grid point and get obtain two three-dimensional arrays (month, latitude, longitude), both of them-which are $12,47,73$, respectively. Then, we calculate probability ratio (PR) $\underline{\mathrm{PR}}$ values using the two arrays in each grid point and set grid points in humid areas as missing values. After that, we convert this new three-dimensional array of PR into ene a one-dimensional array in ascending sequence. Finally, we set the percentile thresholds and draw the figures. (b) (c) -), (c),

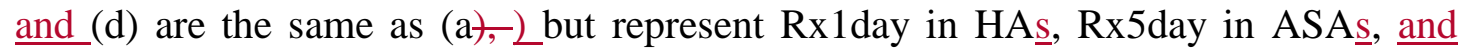
Rx5day in HAs, respectively.

Figure 6. PR spatial changes in $\mathrm{Rx} 1$ day in the $1.5^{\circ} \mathrm{C}$ limits relative to the historical period for (a) $1 \mathrm{pt} 5$, (c) RCP4.5, (e) RCP8.5. All the same but for $2^{\circ} \mathrm{C}$ relative to $1.5^{\circ} \mathrm{C}$ in (b) 2pt, (d) RCP4.5, (f) RCP8.5. The black dotted parts represent ASA . The red dotted parts represent the changes are-passing a 95\% significance test.

Figure 7. The same as figure-Figure 6, but for Rx5day.

Figure 8. Spatial changes in $\mathrm{R} 95 \mathrm{p}$ as a percentage of total precipitation in the $1.5^{\circ} \mathrm{C}$ limits relative to the historical period for (a) 1pt5, (c) RCP4.5, (e) RCP8.5. All the same but for $2^{\circ} \mathrm{C}$ relative to $1.5^{\circ} \mathrm{C}$ for (b) $2 \mathrm{pt}$, (d) $\mathrm{RCP} 4.5$, (f) $\mathrm{RCP} 8.5$. The black dotted parts represent ASA $\underline{s}$. The red dotted parts represent the changes are passing a $95 \%$ significance test. 

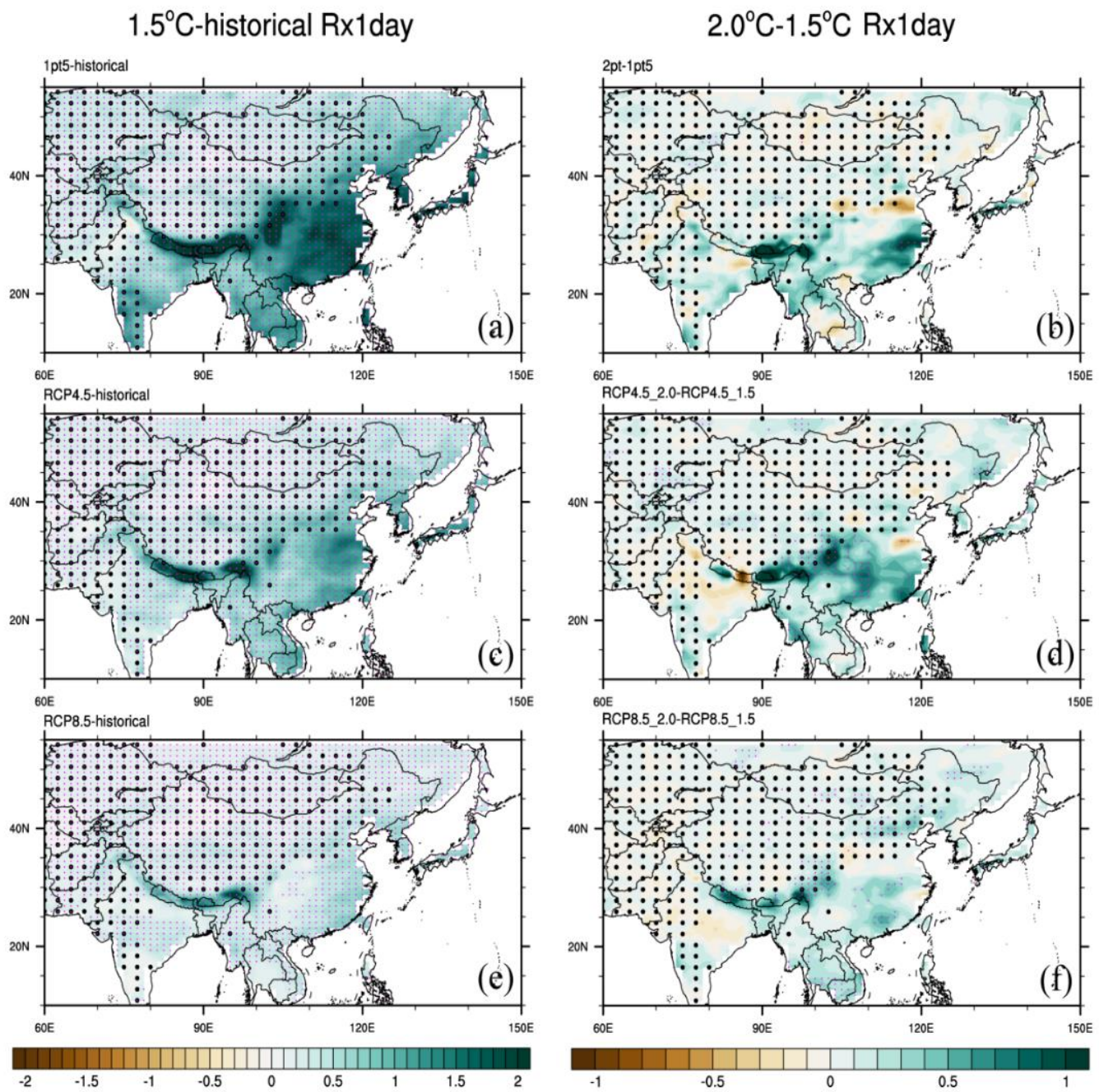

589

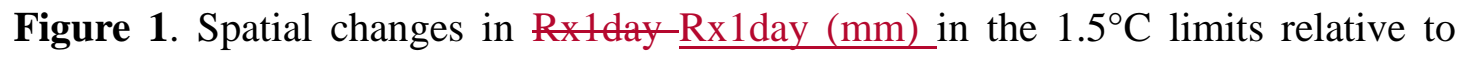

591 (minus, the same below) the historical period for (a) 1pt5, (c) RCP4.5, (e) RCP8.5. All

592 the same but for $2^{\circ} \mathrm{C}$ relative to $1.5^{\circ} \mathrm{C}$ in (b) $2 \mathrm{pt}$, (d) $\mathrm{RCP} 4.5$, (f) RCP8.5. The black 593 dotted parts represent ASAs. The red dotted parts represent the changes are-passing a $59495 \%$ significance test. 

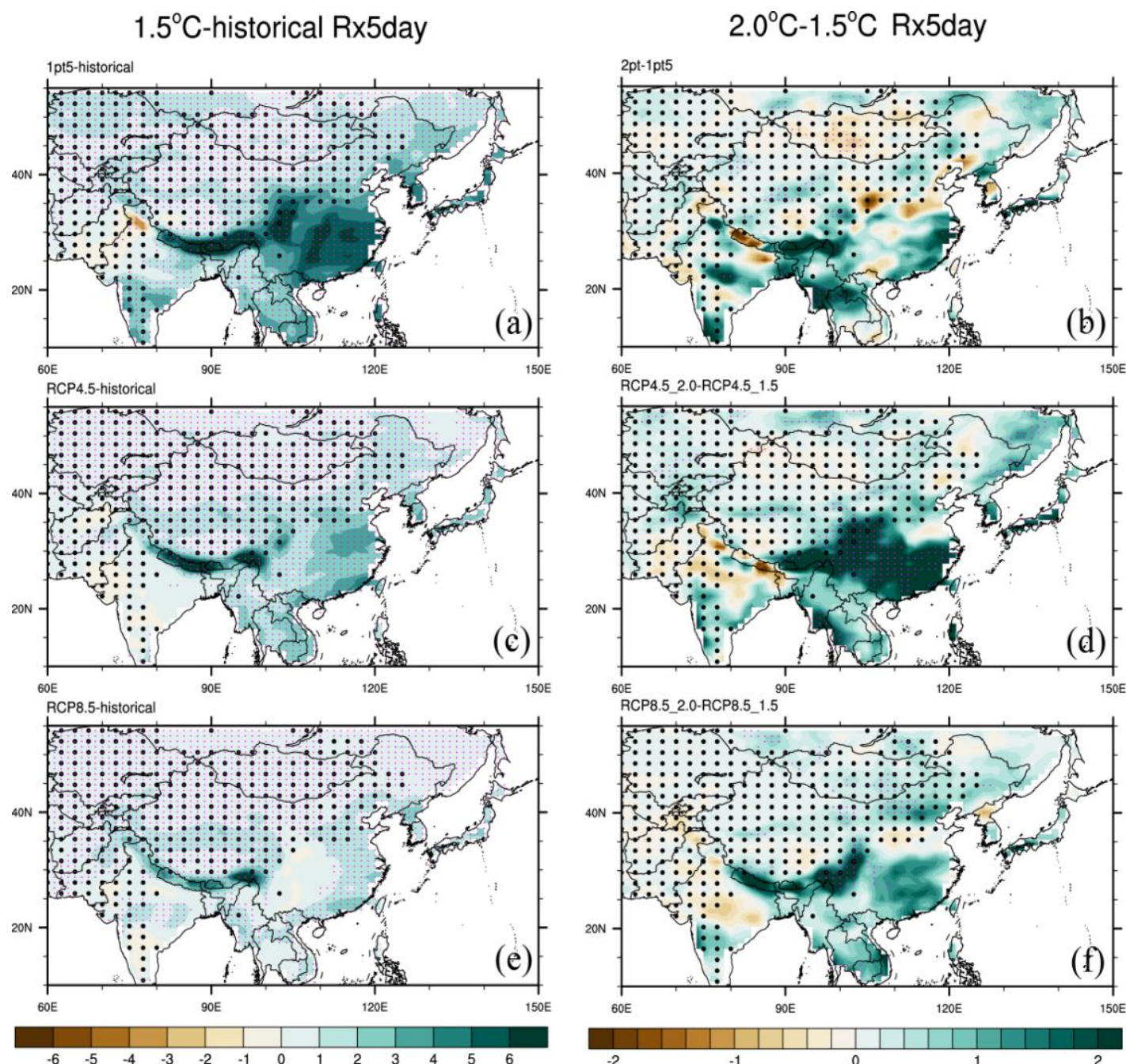

595

596 Figure 2. The same as figure-Figure 1, but for Rx5day- $(\mathrm{mm})$. 

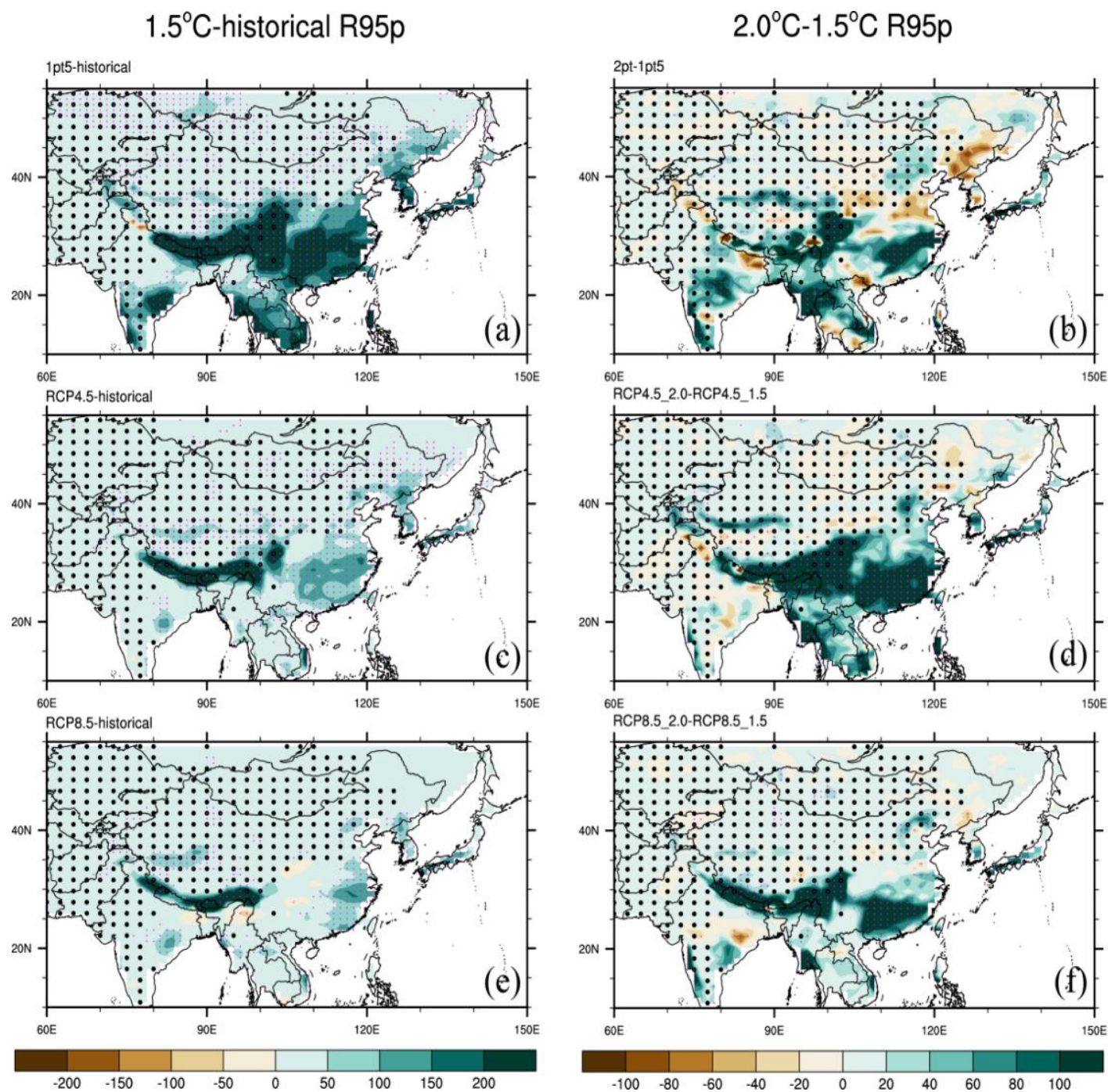

Figure 3. The same as figure-Figure 1, but for R95p $\underline{(\mathrm{mm})}$. 
$1.5^{\circ} \mathrm{C}$-historical SDII
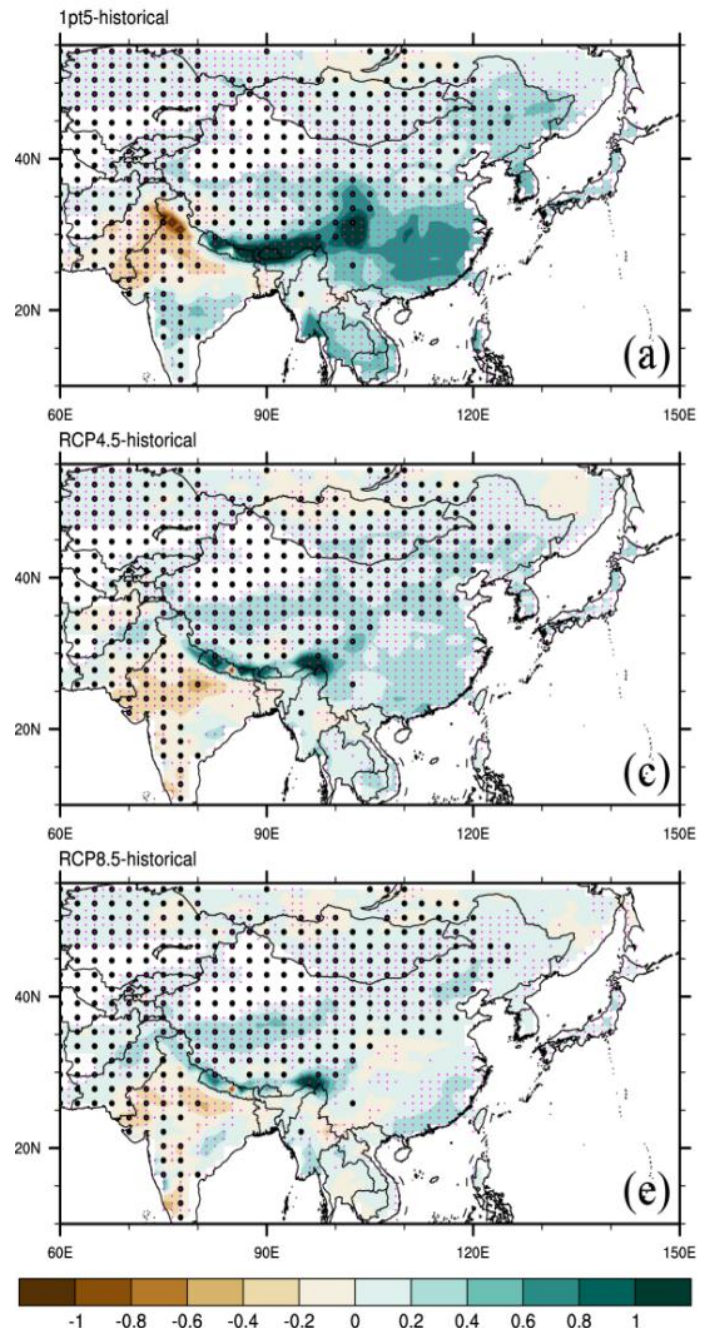

$2.0^{\circ} \mathrm{C}-1.5^{\circ} \mathrm{C}$ SDII
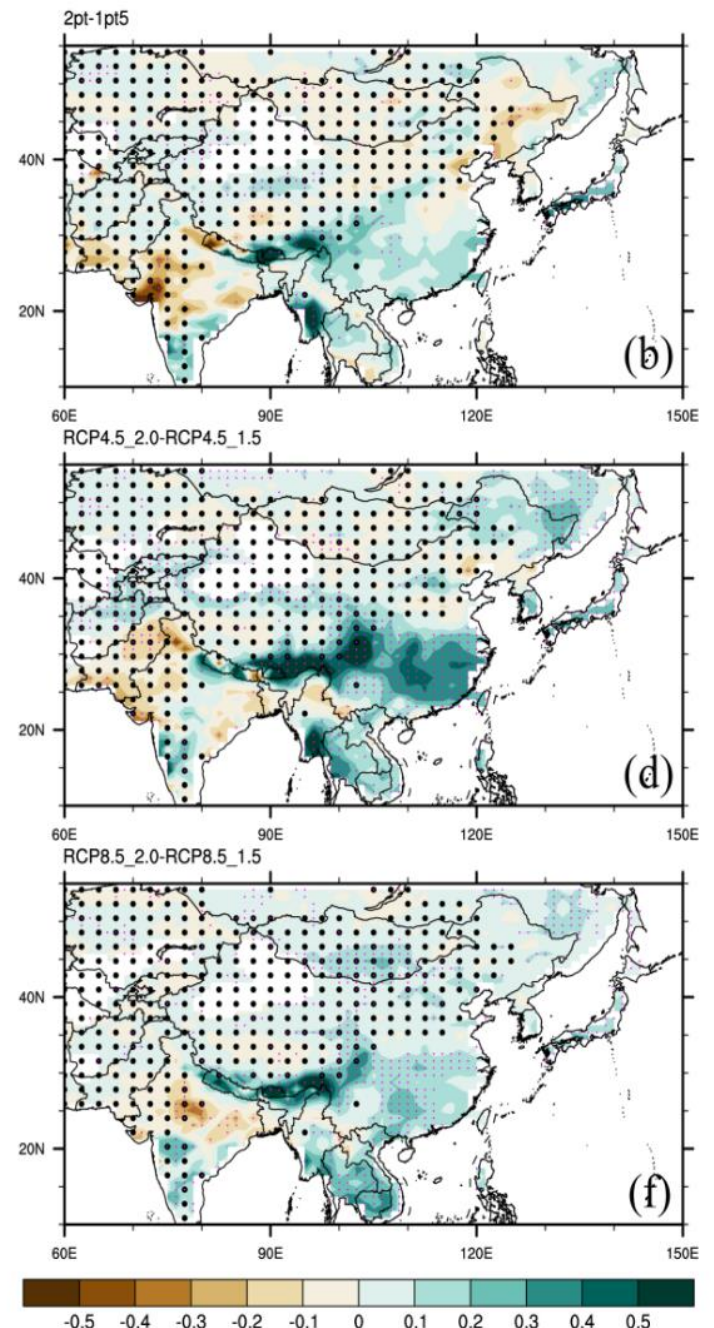

Figure 4. The same as figure-Figure 1, but for SDII (mm/day). 

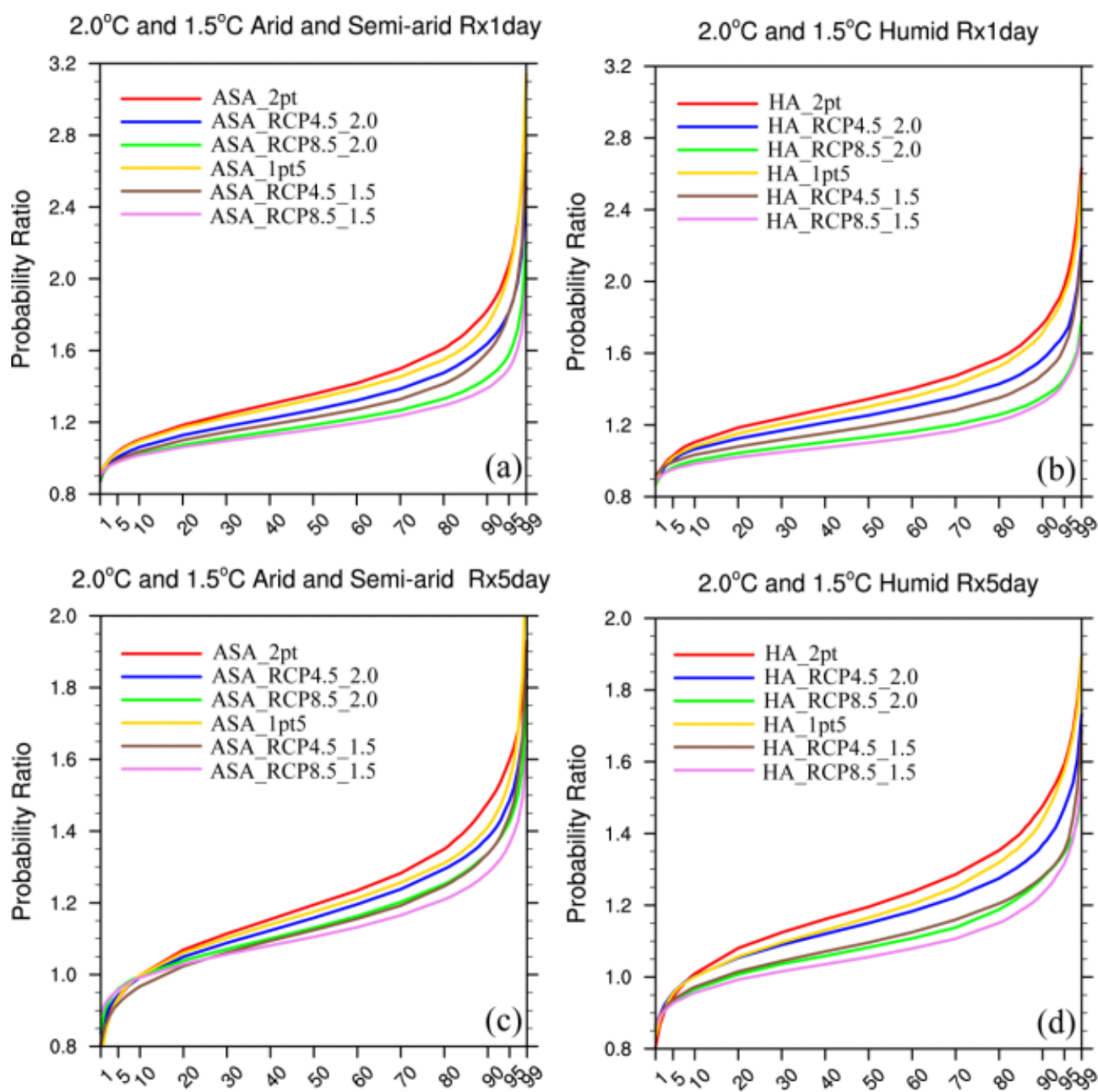

601

602

Figure 5. (a) PR values in Rx1day in ASA $\underline{A S A s}$ under $2^{\circ} \mathrm{C}$ and $1.5^{\circ} \mathrm{C}$ limits relative to the historical period. The $\pm \underline{x-a x i s ~ r e p r e s e n t s ~ t h e ~ p e r c e n t i l e ~ t h r e s h o l d s ~ b a s e d ~ e n-o n ~}$ the historical period. The method is as follows: First, we calculate the Rx1day in $\underline{\text { in }}$ the historical period (average of 30 years) and under the $1.5^{\circ} \mathrm{C}$ warming condition in each grid point and get obtain two three-dimensional arrays (month, latitude, longitude), both of them-which are 12, 47, 73, respectively. Then, we calculate probability ratio (PR)_values using the two arrays in each grid point and set grid points in humid areas as missing values. After that, we convert this new three-dimensional array of PR into ene a one-dimensional array in ascending sequence. Finally, we set the percentile thresholds and draw the figures. (b) (c)-), (c), and (d) are the same as (a), L but represent Rx1day in HAs, Rx5day in ASA $\underline{s}$, and Rx5day in HAs, respectively. 

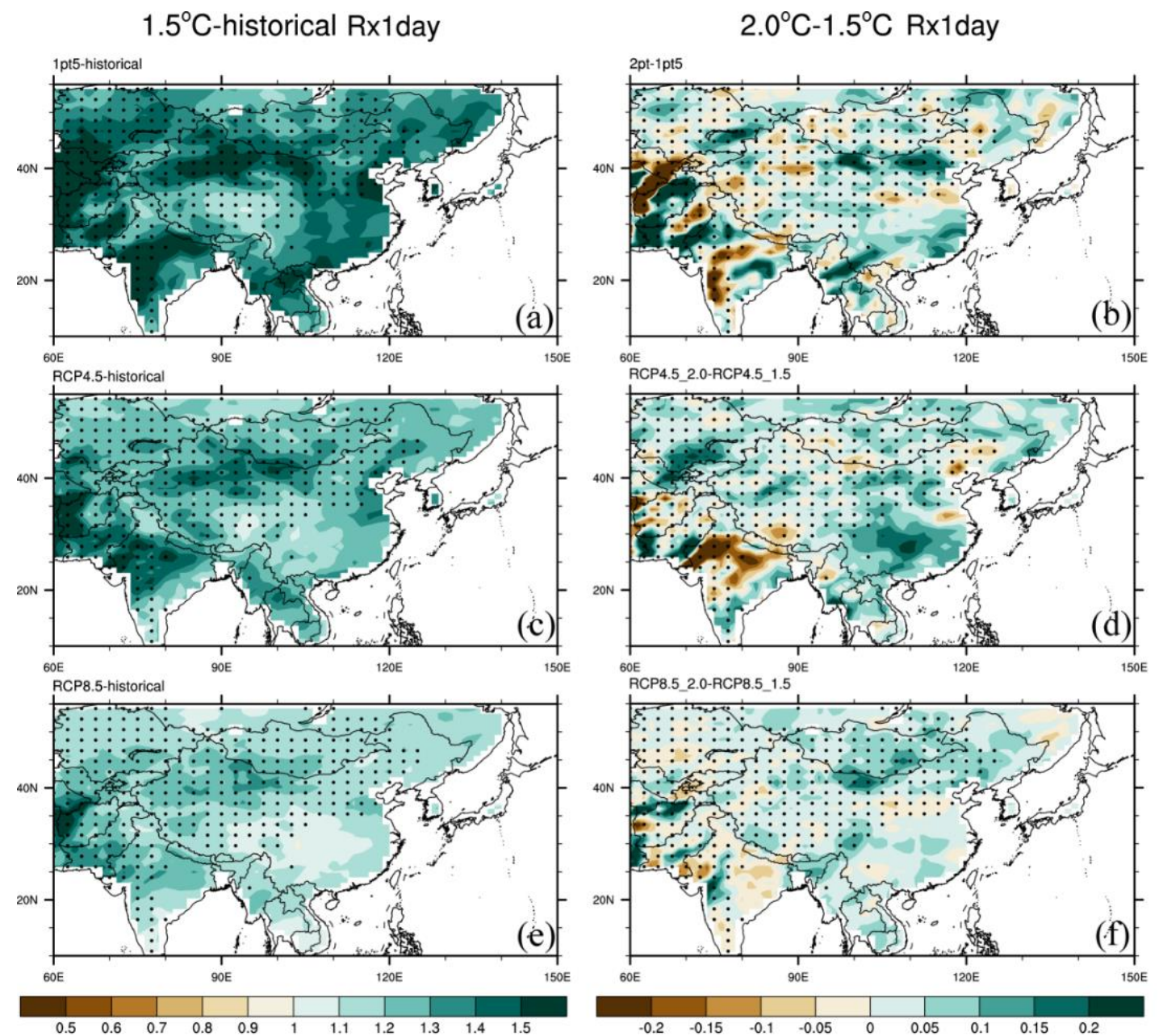

614

less likely | more likely

less likely | more likely

615 Figure 6. PR spatial changes in $\mathrm{Rx} 1$ day in the $1.5^{\circ} \mathrm{C}$ limits relative to the historical 616 period for (a) $1 \mathrm{pt5}$, (c) RCP4.5, (e) RCP8.5. All the same but for $2^{\circ} \mathrm{C}$ relative to $1.5^{\circ} \mathrm{C}$ 617 in (b) 2pt, (d) RCP4.5, (f) RCP8.5. The black dotted parts represent ASA $\underline{\text { s. The red }}$ 618 dotted parts represent the changes are-passing a 95\% significance test. 
$1.5^{\circ} \mathrm{C}$-historical Rx5day
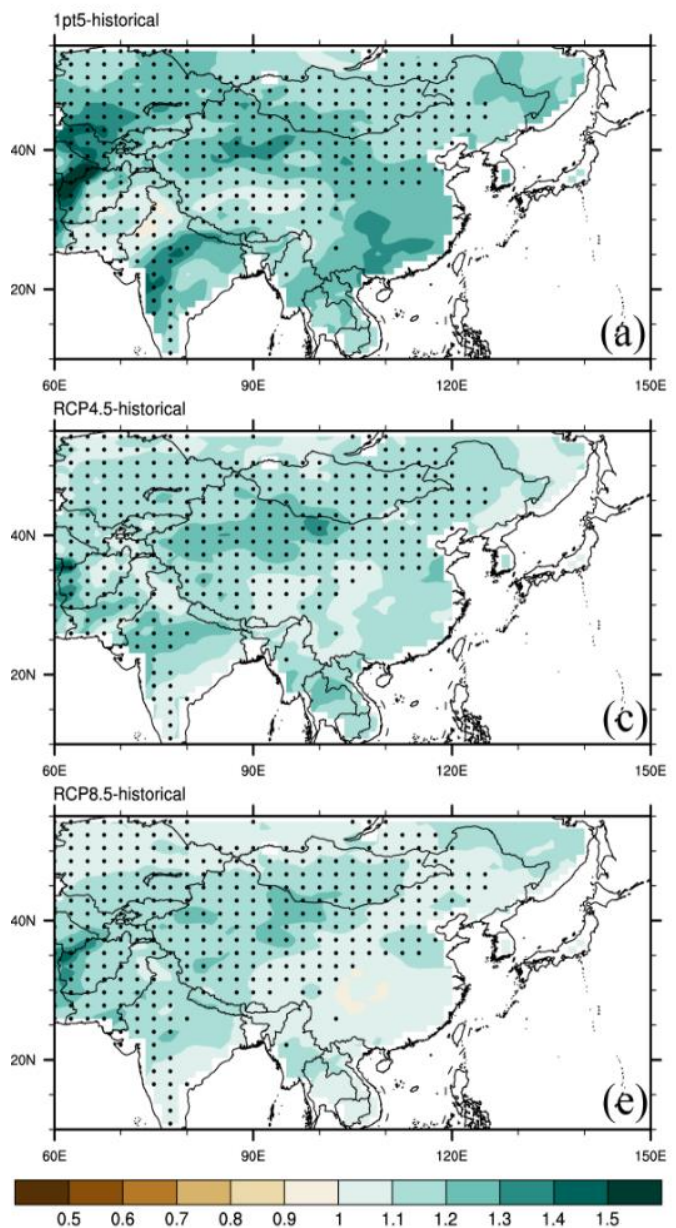

less likely | more likely $2.0^{\circ} \mathrm{C}-1.5^{\circ} \mathrm{C}$ Rx5day
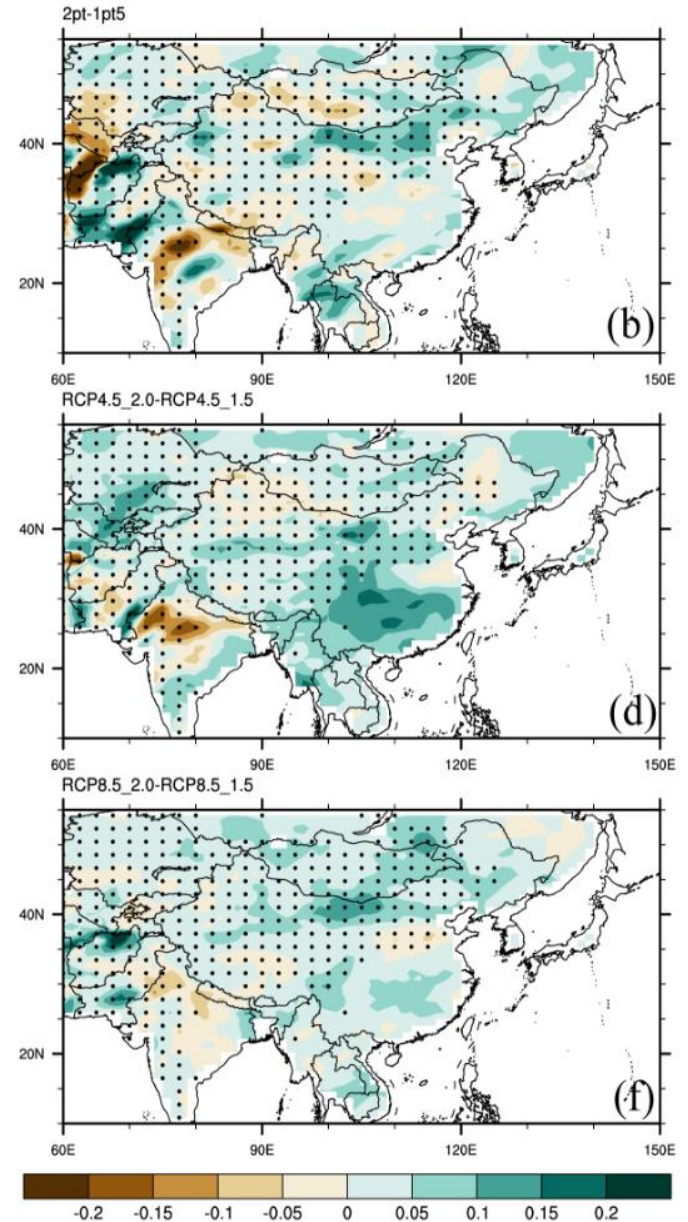

less likely | more likely

620 Figure 7. The same as figure-Figure 6, but for Rx5day-. 
$1.5^{\circ} \mathrm{C}$-historical R95p percent
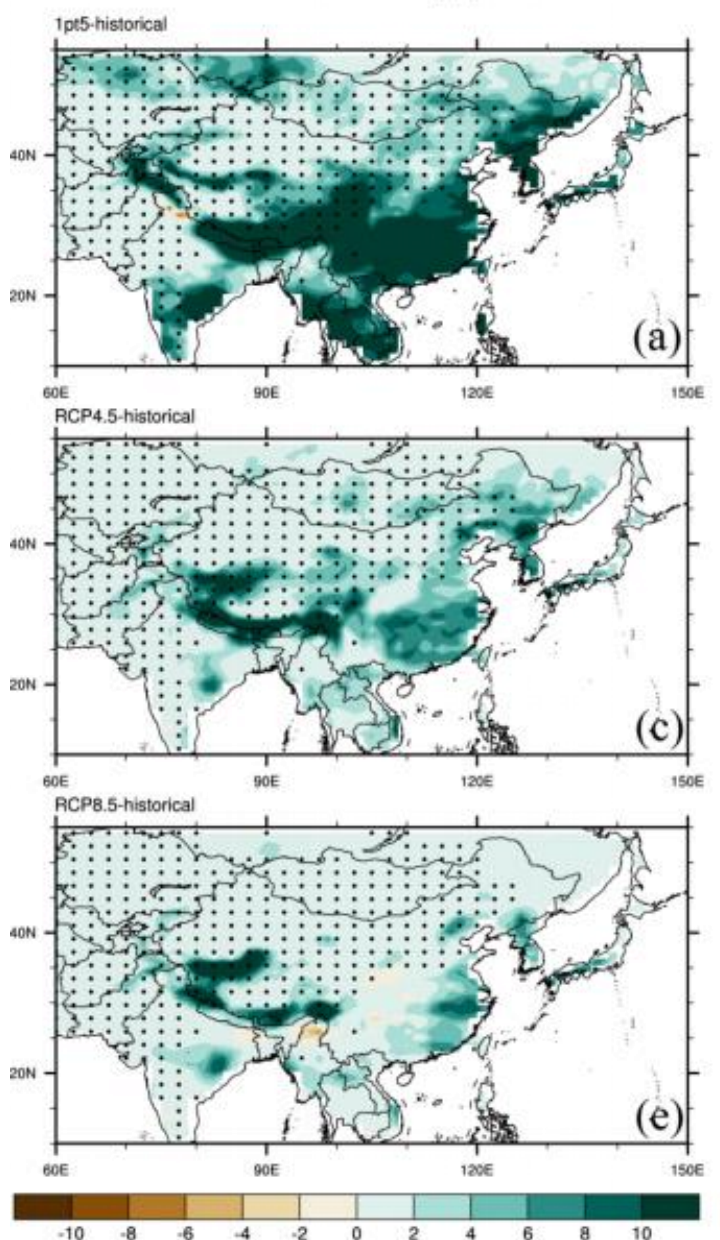

$2.0^{\circ} \mathrm{C}-1.5^{\circ} \mathrm{C}$ R95p percent
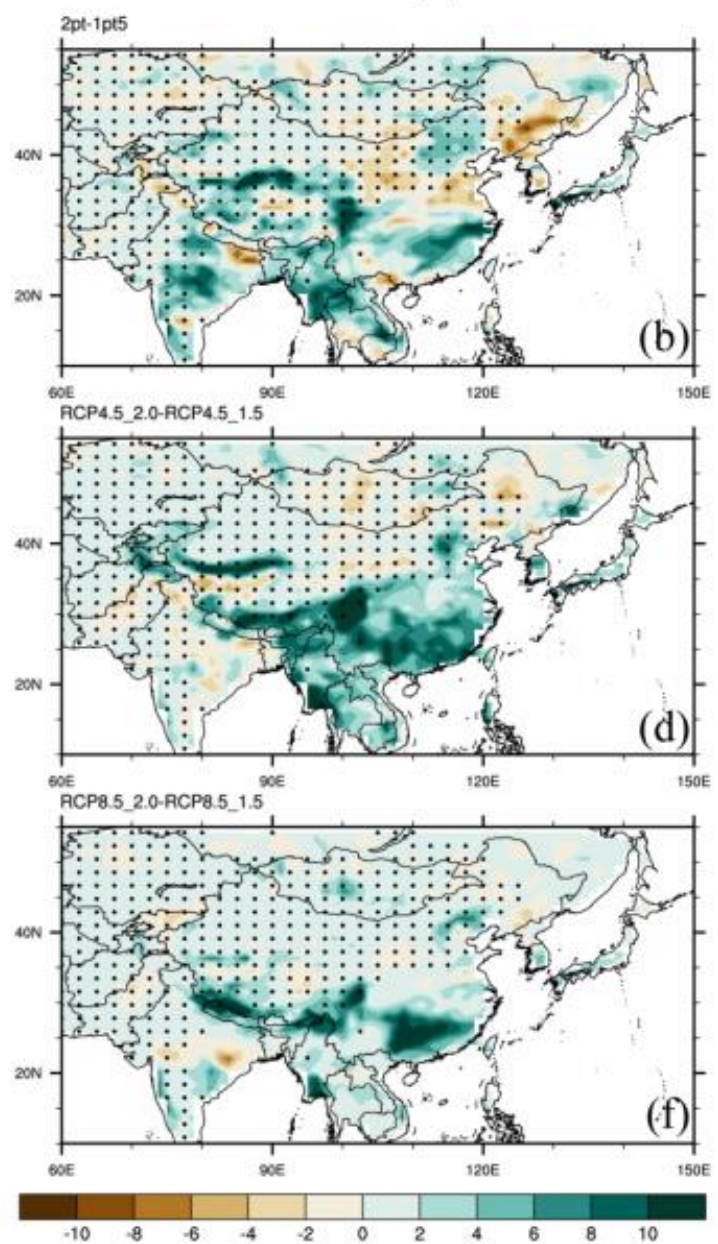

621

622

623

624 625 626

Percentage( $\%)$

Figure 8. Spatial changes in R95p as a percentage of total precipitation in the $1.5^{\circ} \mathrm{C}$ limits relative to the historical period for (a) 1pt5, (c) RCP4.5, (e) RCP8.5. All the same but for $2^{\circ} \mathrm{C}$ relative to $1.5^{\circ} \mathrm{C}$ for (b) $2 \mathrm{pt}$, (d) $\mathrm{RCP} 4.5$, (f) $\mathrm{RCP} 8.5$. The black dotted parts represent ASAs. The red dotted parts represent the changes are-passing a $95 \%$ significance test. 
Date: Mar. 28, 2019

Dr. Haipeng Yu

Northwest Institute of Eco-Environment and Resources

Chinese Academy of Sciences

Lanzhou, China

E-mail: hpyu09@1zu.edu.cn

Dear Editor,

I am writing regarding our revised manuscript entitled "Greater probability of extreme precipitation under $1.5^{\circ} \mathrm{C}$ and $2^{\circ} \mathrm{C}$ warming limits over East-Central Asia”. We are very grateful for your dealing with this manuscript. We are pleased that this manuscript would be accepted conditional on addressing the issues raised by reviewer \#2. Following the suggestions pointed by reviewer \#2, we have revised the manuscript extensively, all the issues have been addressed. The description of $1.5^{\circ} \mathrm{C}$ and $2{ }^{\circ} \mathrm{C}$ warming limits in Section 2.1 has been modified. All the writing mistakes raised by reviewer \#2 has been revised one-by-one. Besides, the English of whole manuscript has been edited by Springer Nature English Language Editting (Order ID KXBTQZK5). Please find all the corrections in the revised manuscript with tracked changes.

We declare that no part of this paper has been previously published or is under consideration for publication elsewhere. We appreciate your attention to our manuscript. If there is any problem, please do not hesitate to contact us.

Sincerely yours,

Haipeng $\mathrm{Yu}$ 


\section{University Library}

\section{- M I N E R VA A gateway to Melbourne's research publications}

Minerva Access is the Institutional Repository of The University of Melbourne

Author/s:

Zhang, M;Yu, H;King, AD;Wei, Y;Huang, J;Ren, Y

Title:

Greater probability of extreme precipitation under $1.5 \#^{\circ} \mathrm{C}$ and $2 \#^{\circ} \mathrm{C}$ warming limits over EastCentral Asia

Date:

2020-05-27

\section{Citation:}

Zhang, M., Yu, H., King, A. D., Wei, Y., Huang, J. \& Ren, Y. (2020). Greater probability of extreme precipitation under $1.5 \#^{\circ} \mathrm{C}$ and $2 \#^{\circ} \mathrm{C}$ warming limits over East-Central Asia. Climatic Change: an interdisciplinary, international journal devoted to the description, causes and implications of climatic change, 162 (2), pp.603-619. https://doi.org/10.1007/ s10584-020-02725-2.

Persistent Link:

http://hdl.handle.net/11343/241632 